DOE/NASA/0152-1

NASA CR-165161

UTRC R81-914724-18

\title{
CATALYTIC COMBUSTION WITH INCOMPLETELY VAPORIZED RESIDUAL FUEL
}

\author{
Thomas J Rosfjord \\ United Technologies Research Center \\ United Technologies Corporation
}

March 1981

Prepared for

NATIONAL AERONAUTICS AND SPACE ADMINISTRATION LewIs Research Center

Under Contract DEN3-152

For

U.S. DEPARTMENT OF ENERGY

Fossil Energy

Office of Coal Utilization 


\section{NOTICE}

This report was prepared to document work sponsored by the United States Government. Neither the United States nor its agent, the United States Department of Energy, nor any Federal employees, nor any of their contractors, subcontractors, or their employees, makes any warranty, ex. press or implied, or assumes any legal liability or responsibility for the ac. curacy, completeness, or usefulness of any information, apparatus, product or process disclosed, or represents that its use would not infringe privately owned rights 
DOE/NASA/0152-1

NASA CR-165161

UTRC R81-914724-18

CATALYTIC COMBUSTION WITH

INCOMPLETELY -VAPORI ZED

RESIDUAL FUEL

Thomas J. Rosfjord

Unıted Technologies Research Center

United rechnologies Corporation

East Hartford, Connecticut 06108

March 1981

Prepared for

Natıonal Aeronautics and Space Administration

Lewis Research Center

Cleveland, Ohio 44135

Under Contract DEN3-152

for

U.S. DEPARTMENT OF ENERGY

Fossil Energy

Office of Coal Utilization

Washington, D.C. 20545

Under Interagency Agreement DE-AI01-77ET-10350 


\section{R81-914724-18 \\ Catalytic Combustion with Incompletely- \\ Vaporized Residual Fuel}

TABLE OF CONTENTS

Page

LIST OF TABLES . . . . . . . . . . . . . . . . . . . . . . . . . . . . . . i

LIST OF FIGURES . . . . . . . . . . . . . . . . . . . . . . . . ii

SUMMARY. . . . . . . . . . . . . . . . . . . . . . . . . 1

SECTION I: INTRODUCTION . . . . . . . . . . . . . . . . . . . 2

SECTION II: TEST SECTION DESIGN . . . . . . . . . . . . . . . . . . 4

Fuel Preparation System. . . . . . . . . . . . . . . . . 4

Catalytic Reactor. . . . . . . . . . . . . . . . . 9

SECTION III: TEST FACILITY AND EQUIPMENT . . . . . . . . . . . . . . . 12

Test Facility . . . . . . . . . . . . . . . . . . 12

Fuel Systems... . . . . . . . . . . . . . . . . . 13

Instrumentation . . . . . . . . . . . . . . . . . . . . . . . 13

Data Acquisition and Reduction . . . . . . . . . . . . . . . . . 14

SECTION IV: TEST RESULTS. . . . . . . . . . . . . . . . . . . . . . 18

Performance with No. 60 . . . . . . . . . . . . . . 18

Performance with Fuel Blends.................. . 22

SECTION V. CONCLUSIONS.. . . . . . . . . . . . . . . . . . . . . . 26

REFERENCES . . . . . . . . . . . . . . . . . . . . . . . . . 27

TABLES . . . . . . . . . . . . . . . . . . . . . . . . . 29

FIGURES. . . . . . . . . . . . . . . . . . . . . . . . . 33

APPENDIX AND DATA TABLES 
R81-914724-18

\section{LIST OF TABLES}

1. Fuel Properties

2. Emissions Analysis Instrumentation

3. Test Parameter Ranges

4. Conditions for No. 6 0il Tests 


\section{LIST OF FIGURES}

1. Physical Events in Monolithic Cell

2 Calculated Atomization of No. 6 Fuel

3 Multiple Venturi Fuel Injector

4. No. 6 Fuel $0_{11}$ Droplet Evaporation Characteristics

5 Fuel Vaporization and Consumption in Catalytic Reactor

6. Graded Cell Catalytic Reactor

7. Residual Fuel Catalytic Reactor Test Rig

8. Catalytic Combustor Facility

9. Test Fuel Delivery System

10 Catalytic Combustor Instrument at ion

11. Catalytic Combustor Sampling Probe

12. Emission Sampling and Analysis System

13. Reactor Performance w1th No. 2011 -- Dependence on Reference Velocity

14 Reactor Performance with No 2011 -- Dependence on Air Preheat

15 Influence of Degree of Vaporization on Reactor Performance Using No. 2 O1l

16. Inconsistent Reactor Performance Dependence on Degree of Vaporization

17. Reactor Performance with Shale 011 Blend -- Dependence on Reference Velocity

18. Influence of Degree of Vaporization on Reactor Performance Using Shale Oil Blend

19 Performance with No. 20 il and 20-percent No. 6 Blend 


\section{SUMMARY}

An experimental program directed toward demonstrating efficient catalytic combustion of fuel-lean mixtures of residual fuel and air, and assessing the influence of incomplete fuel vaporization on the performance of a catalytic reactor has been conducted. A fuel injection system was designed to provide uniform catalytic reactor inlet properties and a controllable level of fuel vaporization. The reactor was a graded-cell device constructed from Corning MCB-12, zirconia-spinel substrate. It was constructed from $5-\mathrm{cm}, 2.5-\mathrm{cm}$, and $17.5-\mathrm{cm}$ lengths of $0.63-\mathrm{cm}, 0.32-\mathrm{cm}$, and $0.16-\mathrm{cm}$ square cell elements, respectively. The elements were catalyzed with a UOP noble metal, proprietary catalyst. The fuel preparation and catalytic reactor components were used in tests with No. 6 oil, No. 2 oil or blends of residual fuel (No. 6 oil or shale residual oil) and No. 2 oil.

Tests performed with incompletely vaporized No. 6 oil did not result in stable combustor operation. The non-vaporized heavy components of the oil impinged on the reactor surface and quenched the catalytic reactions. Streams of luminous particles were observed exiting the reactor when No. 6 oil was used, presumably the result of fuel deposition and subsequent carbonization on the surface, followed by flaking of the deposits into the gas stream. Tests were performed at elevated combustor inlet air temperatures ( 840 to $895 \mathrm{~K}$ ) to achieve complete vaporization of the fuel. In most instances, fuel deposition on the mixer/ vaporizer walls led to a pre-ignition, in one instance, at the highest temperature investigated $(895 \mathrm{~K})$, stable but inefficient combustion was achieved. The several tests performed with No. 6 oil indicated that complete vaporization of the fuel would be required to achieve satisfactory catalytic operation.

Tests were performed with blends of either No. 6 and No. 2 oil, or a shale residual oil and No. 2 oil in an attempt to determine a threshold level of the heavy constituent for satisfactory combustor operation. Test results using the No. 6 oil blend were not repeatable. That is, successful combustor operation was obtanned with a 20-percent No. 6 blend, but could not be reestablished after performing a screening test with a 40-percent No. 6 blend. The body of test data suggested that the non-volatile species contained in the No. 6 was responsible for a change in catalytic activity. In addition, luminous particles were again observed exiting the reactor with all blends containing No. 6 oil; unstable operation and a pre-ignition often accompanied their existence. These results suggested that no level of No. 6 oil was conducive to satisfactory performance unless complete vaporization was achieved. Shale oil blends were identified which resulted in stable operation without bursts of luminous particles exiting the reactor. This fuel differed from the No. 6 oil by having a lower temperature final distillation point, that is, it did not contain the high molecular weight species contained in the No. 6 oil. Tests performed with the shale oil blends indicated that the combustor performance was sensitive to the degree of fuel vaporization. A similar effect was observed in tests performed with No. 2 oil. 


\author{
R81-914724-18 \\ Catalytic Combustion with Incompletely- \\ Vaporized Residual Fuel
}

SECTION I - INTRODUCTION

The current concerns regarding pollutant emissions are occurring at a time when continued development of the gas turbine engine as an industrial prime mover depends in part on its capability to use fuel with far less attractive physical and chemical properties than those of the fuels currently used. Increasingly stringent emission standards prompt even greater emission reductions, particularly of $\mathrm{NO}_{x}$, than may be attainable with current combustor design technology. Therefore, to increase the options available for low emissions, fuel flexible engine designs, novel combustion concepts ought to be investigated. Catalytic combustion appears as an attractive candidate in this application. Considerable effort has been made in developing and demonstrating stable catalytic combustion systems which achieve high combustion efficiency at exceptionally lean fuel-air ratios (e.g., Refs. 1 and 2 ). The preponderence of combustion related work with catalysts has involved the use of either gaseous or relatively volatile fuels coupled with fuel-air preparation systems configured so that a high degree of fuel vaporization was achieved. Among candidate fuels for future gas turbine use are residual fuels, either petroleum or synthetically based, which will be difficult to vaporize. Therefore, it is necessary that investigations be undertaken to elucidate the behavior of catalytic combustion systems using such fuels in lean fuel-air mixtures.

A catalytic combustor is a device in which chemical reactions initiated by a heterogeneous catalyst (i e., catalytic surface) play an important role in the energy release process. The important role of the catalyst makes high values of catalyst surface area per combustor volume desirable. For most applications, the pressure drop through the catalyst bed must be minimal. Therefore, such combustors are primarily constructed from monolithic materials, with ceramic honeycombs being leading candidates. Catalyst is deposited on all exposed surfaces. Such a combustor acts as a bundle of tubular reactors with the energy release occurring as the reactants flow down each tube.

There are several mechanisms which occur in the catalytic reactor. The reactants must diffuse to the catalyst and be adsorbed. Surface chemical reactions occur followed by desorption and diffusion of the products into the bulk flow. Homogeneous gas phase reactions may also be present. The mechanism which controls the energy release process changes as the reactants flow along the tube (Fig. 1). At the inlet, the gas temperature is too low for significant 
gas phase reactions, the lower activation energy surface reactions control. As the surface temperature increases, the heterogeneous reaction rates become greater than the reactant diffusion rates, resulting in a mass-transfer-limited rate of energy release. The gas temperature increases because of heat transfer from the hot surface. In a properly designed reactor, the gas temperature will increase sufficiently for gas phase reactions to dominate, with subsequent rapid consumption of the fuel and partially-oxidized ( $\mathrm{CO}, \mathrm{UHC})$ species. Each of these mechanisms must exist; insufficient surface reactivity will fail to initiate the mechanism chain while the absence of gas-phase reactions will result in poor fuel conversion.

The foregong description applies to reactors fueled with either fullyor mostly-vaporized fuel. The presence of incompletely-vaporized fuel can, however, influence the reactor performance in two ways. First, the presence of fuel in liquid form can reduce the wall temperatures at the inlet, and thus reduce the surface reaction rates, which would at best retard the gas temperature rise, reducing homogenious burnup, or may even destabilize the reactor. The droplets can depress the wall temperatures directly by impinging on the substrate, or indirectly by reducing the gas-phase fuel-air ratio, since it is the consumption of the gas-phase species which provides the energy release required to heat the walls. Second, incompletely-vaporized fuel can require an increased reactor length to allow sufficient residence time to achieve complete consumption of the fuel. In particular, additional length may be required to complete fuel vaporization prior to combustion within the reactor. A catalytic reactor properly designed for incompletely-vaporized fuel would allow for these effects.

United Technologies Research Center (UTRC) under contract with NASA/Lewis Research Center, with funding provided by U.S. Department of Energy has conducted an experimental program directed toward demonstrating efficient catalytic combustion of fuel-lean mixtures of residual fuel and air, and assessing the influence of incomplete fuel vaporization on the performance of a catalytic reactor. The features of the residual fuel, particularly its low volatility and high viscosity, demanded that special considerations be given to the design of a fuel preparation system and catalytic reactor. A fuel injection system was designed to produce highly-atomized sprays of residual fuel by shearing the fuel stream with a high velocity airstream. Control of the fuel atomization was achieved by control of the fuel temperature, and therefore of its viscosity. A $7.6-\mathrm{cm}$ diameter catalytic reactor was designed to combust the incompletelyvaporized residual fuel and air mixture. Design analyses extended techniques applicable to fully-vaporized systems to include considerations of the droplet vaporization and ignition within the catalytic reactor. Acurex Corporation, as a subcontractor to United Technologies, supported UTRC in the design and fabrication of the catalytic reactors. The design details of the injector and reactor, which make up the test section, are described in section II. The capabilities of the test facility, including the details of the rig instrumentation, are included in Section III. Tests were performed over a matrix of conditions to evaluate the influence of changes in inlet air temperature, reference velocity, and combustor fuel-air ratio. The results of the test program are contained in Section IV. 
The test section consisted of two components--the fuel preparation section and the catalytic reactor section. The basis of the designs and the specifications of the final configuration of each of these components are given in the subsections below. The designs depended, of course, on the characteristics of the fuel to be used. The primary test fuel for the program and the fuel for which the test section was designed was a No. 6 residual fuel supplied by NASA. A sample of the fuel was analyzed by Southern Petroleum Laboratories to determine its physical and chemical properties. These data, presented in Table l, were used to develop correlations for the variation of density, viscosity, and surface tension with fuel temperature required to predict the extent of fuel atomization (see below). The distillation characteristics were used to predict the degree of vaporization of the 011 in the mixer/vaporizer duct. As a result of analysis of data obtained in tests using No. 6 ol1 alone, some tests were performed with blends of either No. 6 and No. 2 fuel oll, or residual shale oil and No. 2 fuel o11. The former blends were investigated to determine whether a threshold No. 6 content suitable for acceptable operation could be identified. In the latter blends, another heavy oil (shale) was used to produce mixtures not only less volatile than No. 2, but also without the very high molecular weight species contained in the No. 6/No. 2 blends. Analyses of the shale 011 and the No. 2 o1l are also presented in Table 1.

\section{Fuel Preparation System}

A fuel preparation system consisting of a fuel injector and a mixer/ vaporizer duct was designed to inject No. 6 fuel oil and satisfy three operational requirements at the following conditions: inlet air temperature $=$ $600 \mathrm{~K}$; pressure $=0.6 \mathrm{MPa}$; reference velocity $=20 \mathrm{~m} / \mathrm{s}$; and fuel-air rat $10=$ 0.020 . The first requirement, which was derived from the operational characteristics of a catalytic combustor, was that the system must provide distributions of fuel-air ratio, temperature and velocity which were uniform to within \pm 10 percent of the mean value at the catalytic reactor inlet. Since the reactor would act as a bundle of independent tubular reactors, uniform inlet profiles were desirable both to maximize the effectiveness of the entire frontal area and, since currently avallable substrates have continuous use temperatures marginally in excess of desired flame temperatures, to avoid substrate damage resulting from the temperatures produced from locally enriched fuel-air mixtures. The second and third requirements for the fuel preparation system related to producing an incompletely-vaporized fuel-air mixture. In particular, the fuel injection system was required to produce sprays characterized by a Sauter Mean Diameter (SMD) of either less than $30 \mathrm{microns}$ or in the range of $70-150 \mathrm{mlcrons}$. In addition, it was required that less than 50 percent of the fuel be vaporized at the catalytic reactor inlet. 
Previous efforts to develop a fuel injector suitable for use with catalytic reactors have included evaluations of a variety of fuel injector configurations. Tacina (Refs. 3 and 4) has been particularly active in this area reporting on the fuel spatial distribution for an array of multiple-jet spraybars, centrally-mounted splash groove injectors, simplex pressure-atomizing (coflow and contraflow) and sonic arr-assisted fuel injectors, and a multiple-conicaltube injector. Characterization tests of the latter device have shown it to be an attractive technique to achieve spatially uniform fuel-air mixtures. In the Tacina design, 21 conical tubes were bundled across the flow area with fuel injected into the smaller, upstream end of each. This configuration provided both a reasonable number of injection sites across the airflow and control of the air velocity at the fuel injection site. The blockage provided by the bundle imposed a pressure drop which reduced airflow nonuniformities and increased the air velocity at the fuel tube to enhance fuel atomization and mixing with the air. Fuel-air ratio distributions within \pm 10 percent of the mean were obtained for a $20 \mathrm{~m} / \mathrm{s}$ reference velocity at a distance of $18 \mathrm{~cm}$ downstream of the fuel injection location.

An injector embodying the concepts of the Tacina design has also been used at UTRC (Ref. 5). This device included 19 convergent/divergent venturi tubes packaged to cover a $10.2-\mathrm{cm}$ diameter flow area. Characterization tests of this injector demonstrated its ability to achieve uniform fuel-air distributions to within \pm 10 percent of the mean at a downstream distance of $30 \mathrm{~cm}$ for conditions similar to those of this program. (Characterization tests were not performed at shorter distances.)

The demonstrated ability of the multiple-venturi concept to produce nearly-uniform fuel-air ratio distributions prompted adopting this concept for this program.

In a multiple-venturi injector, the fuel is injected perpendicular to the airstream through a tube in each throat and atomized by the strong air-blast effect. Several investigations have been performed to characterize the SMD of sprays produced by air-blast injectors. Review of these investigations (Refs. 6 through 9) led to the selection of the correlation developed by Jasuja (Ref. 7) as applicable for the multiple-venturi injector. The correlation developed was:

$$
\operatorname{SMD}=0.19 \frac{\left(\sigma_{\ell} / \rho_{\ell}\right)}{u_{a}{ }^{0} 0.35}{ }^{0.35}\left(1+\frac{1}{\mathrm{AFR}}\right)^{0.25}+0.127 \mu_{\ell}\left(\frac{D}{\rho_{\ell} \sigma_{\ell}}\right)^{0.50}\left(1+\frac{1}{\mathrm{AFR}}\right)
$$


where. SMD - droplet diameter, m

$\sigma_{\ell}-1$ iquid surface tension, $N / m$

$\rho_{\ell}$ - liquid density $\mathrm{kg} / \mathrm{m}^{3}$

$\mu_{\ell}$ - liquid viscosity, $\mathrm{Ns} / \mathrm{m}^{2}$

$\rho_{\text {a }}$ - air density, $\mathrm{kg} / \mathrm{m}^{3}$

$\mu_{a}^{a}$ - air velocity, $\mathrm{m} / \mathrm{s}$

D - orifice diameter, m

$A F R$ - air to fuel ratio in injector by weight

The correlation is the sum of two terms, the first 19 dominated by the air velocity while the second is responsive to the liquid (i.e., fuel) viscosity. Proper design of injector blockage and selection of fuel temperature would produce the air velocity and fuel viscosity, respectively, which would result in calculated droplet sizes which satisfied the requirements of the program. In order to produce small droplets both terms were minimized by having a high air velocity and low viscosity. Calculations using the properties of the test fuel led to the specification of a venturi throat diameter of $0.54 \mathrm{~cm}$ to produce a velocity of $245 \mathrm{~m} / \mathrm{s}$ at the fuel injection site, insuring that the first term of the atomization correlation would always have a small value. Larger diameter droplets were to be obtained by allowing a higher viscosity (lower fuel temperature) which overrode the atomzing tendency of the high air flow. Analyses based on a $0.76-\mathrm{mm}$ inside diameter fuel tube and the fuel properties indicated that for a fuel temperature of $373 \mathrm{~K}$, a spray characterized by an SMD of 25 microns would have been obtained, while at a temperature of $329 \mathrm{~K}$ a spray having an SMD of 100 microns would be formed. The tradeof $f$ in the droplet diameter with fuel temperature for the range of reference velocities investigated in this program is shown in Figure 2.

As a result of the atomization analyses, an injector containing 19 venturi tubes distributed over a $7.6 \mathrm{~cm}$-diameter circular area was fabricated (F1g. 3) The injector was fabricated by an electrical-discharge machining technique to permit the 7-deg conical half angle diffusers to terminate along the natural cone intersections. This geometry eliminated regions of recirculating base flow which would have promoted autoignition within the fuel preparation system. The test fuel tubes had an internal diameter of $0.76 \mathrm{~mm}$, were $28 \mathrm{~cm}$ long and penetrated 30 percent across each venturi throat. A test fuel tube was located at the throat of each venturi; a Jet A fuel tube ( $0.58 \mathrm{~mm} \mathrm{ID,} 152 \mathrm{~cm}$ long), used to inject fuel during reactor start-up, was located $0.5 \mathrm{~cm}$ directly upstream from each test fuel tube. A $0.4-\mathrm{cm}$ diameter well was milled into the injector body for each fuel tube to provide an air gap between the tube and the body, drminishing the potential to overheat the fuel. Each set of fuel tubes was calibrated to assure that it consisted of fluid mechanically equivalent tubes.

The design of the mixer/vaporizer duct was based upon numerical analyses of the fuel vaporızation and fuel-air mixing process by exercizing the UTRC Spray 
Vaporization Program. This code employs an axisymmetric or two-dimensional stream tube calculation technique developed to analyze fuel spray behavior. Fuel vaporization and droplet and gas phase mixing were modeled through consideration of the convective and diffusive exchange of mass, momentum, and energy between the stream tubes. The initial profiles of gaseous and liquid phase properties (temperature, velocity, droplet size, species concentration, etc.) and the flow geometry were specified. The governing equations were solved by a forward-marching, finite-difference procedure which provided a streamwise evolution of the two-phase flow properties. Radiation from the catalytic reactor to the liquid droplets was not considered in the UTRC Spray Vaporization Program. Radiation was expected to influence the vaporization when the droplets were approximately $2 \mathrm{~cm}$ upstream of the reactor inlet but this effect was considered to be part of the reaction process since the extent of evaporation induced by back radiation would depend upon the thermal condition and geometric configuration of the reactor.

The mixer/vaporizer design calculations were based upon represent ing the fuel as a pure substance with a vapor pressure which corresponded to the 25 percent point of the No. 6 distillation characteristic--half of the maximum desired extent of evaporation. Design calculatzons were performed for cases in which fuel droplets with diameters of 30 and 35 microns at initial temperatures of $373 \mathrm{~K}$ and of 100 microns at $329 \mathrm{~K}$ were injected into an airstream. The initial air velocity was assumed to be $245 \mathrm{~m} / \mathrm{s}$ as would exist at the throat of any one of the 19 fuel injector venturi throats, the air velocity then decreased in accordance with the area change associated with the 7-deg half-angle diffuser prior to assuming a constant value corresponding to the mixer/vaporizer air velocity. The maximum allowable spray SMD at the injector was approximately 35 microns in order to simultaneously limit the vaporization to the 50 percent maximum limit and achieve a mean droplet diameter of less than 30 microns at the reactor inlet. Therefore, as shown by the calculation results (F1g. 4) the mixer/vaporizer had to be shorter than $19 \mathrm{~cm}$. If smaller droplets were produced, a shorter length mixer/vaporizer would be required to remain below the vaporization limit. Note that over this length the larger droplets would have vaporized to a much smaller extent, after $19 \mathrm{~cm}$, a droplet initially with a dlameter of 100 microns would vaporize only 10 percent. The length required by the large droplet to achieve 50 percent vaporization was approximately one meter, an impractical length for either this test program or a conventional engine configuration. Since the gaseous fuel-air ratio corresponding to 10-percent fuel vaporization was below the minimum at which catalytic combustors had been operated with distillate fuel, there was a concern that the reactor would be ineffective. It was recognized, however, that tests could be performed with intermediate droplet sizes (produced by raising the fuel temperature) which would provide more favorable levels of vaporization. This approach was compatible with the fuel injection system and of fered the opportunity to define an operational limit. 
During the course of the test program, as a result of an internallysponsored UTRC program, the Spray Vaporization Program was modified to treat multicomponent fuels using a technique based upon the work of Cox (Ref. 10). Cox assumed that at any instant during the vaporization process the behavior of the distillate fuel could be represented by that of a pure substance, however, different pure substances characterized the fuel as the droplet vaporized. This technique simulated a droplet in which the lighter components were preferentially-vaporized while the relatively non-volatile species were retained. The full distillation curve (which was obtained at one atmosphere) was used to determine the representative pure substance at any instant. The expected level of fuel vaporization was recalculated after acquiring the capability to track the complete fuel distillation signature. The results, also shown in Figure 4, were significantly different from those obtained in the design activity. Initially, the vaporization gradient (change of vaporization with distance traveled) was higher, reflecting the vaporization of the low molecular werght components ("light ends"), while further along the duct the gradient fell to a relatively low level. This character indicated that the droplet was approaching a steady state temperature at which the vapor pressure of the remaining components, and hence the droplet vaporization rate, was low. Whereas the design calculations indicated that 50 percent vaporization would be achleved at a distance $18 \mathrm{~cm}$ from the fuel tube for a 35-micron diameter droplet, the improved calculation procedure predicted only a 30 percent level. Higher degrees of vaporization were predicted for smaller droplets which heated more rapidly (higher surface-to-volume rat 10), providing relatively high vapor pressures and vaporization rates in the initial portion of the mixer/vaporizer. This higher vapor pressure decreased further down the duct because only the relatively non-volatile components remained. As indicated above, the ability to perform these calculations was attained subsequent to the design of the mixer/vaporizer, the device used in the test program was based on the single component representation of the fuel. As a result of the improved calculation results tests were performed with smaller initial droplet diameters and elevated air temperatures to achieve the level of vaporizaton sought in the original design.

The mixing of the injected fuel into the alrstream was also analyzed using the UTRC Spray Vaporization Program. The 1nitial fuel concentration was represented as a "tophat" profile (centered on the longitudinal axis of the venturi) with a width equal to two fuel tube diameters. An eddy diffusivity equal to the value determined by Longwell (Ref. 11) for the turbulent transport of fuel droplets was employed. Results of calculations indicated that a fuel-air mixture uniformity within approximately \pm 5 percent of the mean would be achieved $13 \mathrm{~cm}$ downstream from the fuel tube. The calculations also indicated that a uniform air velocity profile would also be realized. Tacina (Ref. 4) obtained uniformity at $17.8 \mathrm{~cm}$ downstream from a jet fuel, multipleventuri injector configured to distribute 21 injection sites over a $12-\mathrm{cm}$ diameter circular area. The injector fabricated for this program had 19 sites distributed over a $7.6-\mathrm{cm}$ diameter, which provided an injection site 
density 2.2 times the Tacina design. Assuming a similar mixing rate, the decreased distance between injection sites should result in uniformity at $12 \mathrm{~cm}$ downstream from the fuel tube. It was recognized that, because of differences in the fuel spray (fuel properties, droplet sizes) and the precise injector geometry, the consistency of this prediction with the UTRC model calculations did not guarantee the mixer performance. The agreement did, however, establish a level of confidence in the design procedure. Additionally, based upon the vaporization calculations presented above, the mixer/vaporizer length was specified at $18 \mathrm{~cm}$ providing even greater distance to achieve greater property uniformity.

As initially fabricated, the mixer/vaporizer duct was a metal sleeve, with an inside diameter of $7.6 \mathrm{~cm}$. A later design utilized a sleeve of Carborundum T30R Fiberfrax insulation with a sheet-metal liner to provide the same inside diameter. This design was expected to achieve a higher inside wall temperature thereby diminishing the tendency of the fuel to condense on the wall.

The design of the fuel preparation section (injector and mixer/vaporizer) was based upon the existing atomization correlation and analytical calculations of the vaporization and mixing processes. Diagnostic techniques were not employed to verify that the stipulations regarding property distribution, droplet diameter or fuel vaporization were satisfied. The efforts of the program were focused on determining the gross effects resulting from operation of a catalytic reactor with incompletely-vaporized residual fuel.

\section{Catalytic Reactor}

Acurex Corporation, as a subcontractor to UTRC, designed the catalytic reactor used in the tests with No. 6 oil. A detalled account of their design procedure is contained in Ref. 12, the following summarizes their effort.

A 7.6-cm diameter reactor was designed to achieve a 99.5 percent combustion efficrency of No. 6 oil at the following condition: inlet air temperature = $600 \mathrm{~K}$; pressure $=0.6 \mathrm{MPa}$, reference veloc1ty $=20 \mathrm{~m} / \mathrm{s}$, and adrabatic combustion temperature $=1400 \mathrm{~K}$. A 50 percent level of fuel vaporization was assumed. A three-phase design analysis was performed. In the initial phase, it was assumed that the reactor was adiabatic and the fuel dro-lets did not ignite. The second analysis phase superimposed the droplet combustion phenomena on the initial results by considering the ignition and combustion times for the droplets within the reactor. The third phase of the analysis considered the non-adiabatic characteristics of the reactor, particularly the destabilizing influence of radiation from the upstream face of the bed. 
In the initial adiabatic analysis, governing differential equations for the bulk gas energy and mass balances, droplet energy and mass balances, and surface energy balance were solved using a finite difference procedure. Surface catalytic rates would control the energy release at the inlet of the reactor. However, because of the lack of quantitative data on kinetic rates for residual fuel and air catalytic reaction, it was assumed that the fuel consumption rate was diffusion limited. An initial catalytic reactor configuration was selected based upon past experience with the combustion of highlyvaporized No. 6 fuel oll (Ref. 13). This device was patterned after a gradedcel1 concept which had been investigated by Acurex (Ref. 14). This graded-cell catalytic reactor was a device in which the cell diameters become progressively smaller along the streamwise direction; larger cell honeycomb substrates were used at the catalytic reactor inlet, while smaller cell diameter elements were used near the reactor exit. Most of the reactor length consisted of small cell diameter elements which were required to achieve complete burn-up of the partially-oxidized species. The larger cells at the reactor entrance promoted stable operation. That is, since the fuel consumption rate was controlled by the surface catalytic rates at the entrance, it was desirable to obtain high substrate temperature to maximize these rates. Heat loss to the convecting airstream was minimized by using large cell diameters thereby reducing the heat transfer coefficients. The rate of fuel conversion would not be affected since surface reaction rates, and not transport processes, were controlling.

The initial reactor investigated was configured to include $5-\mathrm{cm}, 2.5-\mathrm{cm}$, and $15-\mathrm{cm}$ lengths of $0.63-\mathrm{cm}, 0.32-\mathrm{cm}$, and $0.16-\mathrm{cm}$ diameter cell monolithic substrates, respectively. A typical result from the adiabatic analysis is shown in Fig. 5 which depicts the variation in the substrate temperature, bulk gas temperature, droplet radius, local gaseous fuel-air ratio, and fuel conversion efficiency with distance along the reactor length at the design condition. As indicated, the events were guided by the droplet evaporation. As the droplet vanished the wall temperature increased to the adiabatic temperature and the bulk gas temperature and the fuel conversion efficiency increased more rapidly. These results indicated that in the absence of homogeneous combustion or droplet ignition the goal of 99.5 percent combustion efficiency would require a reactor length significantly in excess of $25 \mathrm{~cm}$. These results were for a mass-transfer-11mited system, and therefore were conservative. That 1s, at the temperature levels experienced in the latter parts of the reactor, homogeneous gas phase reactions would dominate and rapidly consume the partiallyoxidized species. With these reactions it was estimated that the fuel would be consumed a few centimeters after complete evaporation of the fuel droplet, for a total reactor length of approximately $24 \mathrm{~cm}$. Note that these calculated reactor lengths were considerably in excess of reactors designed for operation on light-distillate fuels (e.g., Jet A). In essence, the device designed for residual fuel provided the additional length (residence time) required to achieve complete evaporation of the relatively non-volatile components. This 
was not identical to providing a similarly longer mixer/vaporizer as the droplet evaporation rate within the reactor would be higher than experienced within the mixer/vaporizer because of the intense temperature field within the cells. In addition to projecting reactor lengths for adiabatic operation, the analysis provided the gas and droplet temperature histories required to calculate the distance traveled by the droplet prior to ignition. Using these results, the calculated ignition length was approximately $21 \mathrm{~cm}$, with complete combustion of the droplet occurring within two additional centimeters.

The reactor performance calculations indicated that an approximately $24-\mathrm{cm}$ long device would be sufficient to completely consume the fuel. An implicit assumption was that the reactor would operate stabily, that is, the substrate at the reactor inlet would remain hot enough to adequately promote the surface catalytic reactions. One influence on the substrate temperature was the upstream radiation loss from the reactor inlet. An analys is of this effect indicated that approximately a $100 \mathrm{~K}$ depression in the substrate temperature would be experienced on the face, the radiation loss would af fect the temperature of the initial 2-cm length of the catalytic reactor. Therefore the length of the large cell elements was chosen to be greater than the penetration of the temperature depression.

It was also recognized that the presence of non-vaporized fuel could destabilize the reactor by either lmpinging on the reactor surface or by reducing the gas-phase fuel-air ratio. The former affect was minimized with the graded-cell concept by providing large flow channels at the inlet of the reactor. In an attempt to minimize the second effect, a catalyst preparation available from UOP was selected. Previous Acurex experience indicated it to be an active catalyst, of fering the possiblity of acceptable activity even at the temperature as sociated with the reduced gas-phase fuel-air ratio. (Note that with the 50 percent vaporization limit, this fuel-air ratio would be half the overall value, being as low as 0.010 for simulated gas turbine operation.)

Based upon analyses of several reactor geometries at the design condition and near-design conditions, the reactor was specified to be a $7.6-\mathrm{cm}$ diameter, graded-cell device made with Corning MCB-12 zirconia-spinel substrate (Fig. 6). Catalytic elements, each $2.5-\mathrm{cm}$ thick, were assembled into $5-\mathrm{cm}, 2.5-\mathrm{cm}$, and $17.5-\mathrm{cm}$ lengths of $0.63-\mathrm{cm}, 0.32-\mathrm{cm}$, and $0.16-\mathrm{cm}$ square cell segments, respectively. The elements were catalyzed with a UOP noble metal, proprietary catalyst. The reactor was assembled by Acurex and instrumented with high temperature thermocouples embedded in a dedicated substrate channel. The as sembled segments were cemented into a Carborundum Fiberfrax T3OR sleeve for insertion into the test rig. The Fiberfrax sleeve had a nominal 1.2-cm wall thickness which reduced heat loss from the reactor to less than one percent of the energy released. 


\section{SECTION III - TEST FACILITY AND EQUIPMENT}

The test program was conducted in the Jet Burner Test Stand (JBTS) located at UTRC. This section of the report describes the test facility including the air inlet and exhaust sections and the fuel delivery system required for residual fuel. Also specified are the test rig instrumentation, including a description of the gas sampling probe and the analysis instruments, the data acquisition system, and data reduction procedures.

\section{Test Facility}

The test facility assembled for this program is shown schematically in Fig 7, a photograph is included in Fig. 8. The facility consisted of an arr inlet section, test section, and exhaust section.

The air inlet section provided alrflow to the test section which satisfled the requirements of the test matrix. Air was supplied to the JBTS by multi-stage reciprocating compressors which could provide continuous alrflow rates up to $4.5 \mathrm{~kg} / \mathrm{s}$ at pressures up to $2.5 \mathrm{MPa}$. The flow rate to the rig was determined using an ASME venturi sized to operate choked. An electrical resistance-type air heater capable of heating airflows in excess of $1.5 \mathrm{~kg} / \mathrm{s}$ to $600 \mathrm{~K}$ was used; alrflows up to $0.5 \mathrm{~kg} / \mathrm{s}$ could be heated to $900 \mathrm{~K}$. A plenum with internal flow straighteners was used to transition from the heater to the test section and provide a uniform velocity profile.

The test section was constructed from commercially available pipe having an inside diameter of $10.2 \mathrm{~cm}$. The multiple-venturi injector was clamped between flanges wh the diffuser cones inserted into the $7.6-\mathrm{cm}$ diameter constant area portion of the mixer/vaporizer. The catalytic reactor was mounted in a sleeve of Carborundum Fiberfrax T30R to insulate against heat losses from the reactor. The gas phase reactor was a tubular extension of the catalytic reactor, $45 \mathrm{~cm}$ long with a $7.6-\mathrm{cm}$ inside diameter. It consisted of another sleeve of Fiberfrax within a standard pipe to reduce heat loss to less than one percent of the energy released. A $0.7-\mathrm{mm}$ thick sleeve of Hastelloy was inserted inside the Fiberfrax to minimize erosion of the insulator. The details of the design of the fuel injector, mixer/vaporizer, and catalytic reactor are contaned in Section II

The exhaust section contained two important components--a viewport and a back pressure valve. The viewport was a $7.6-\mathrm{cm}$ diameter quartz window which provided direct observation of the reactor exit plane via an avallable closed circult television system. The video image was monitored in the control room and recorded with a audio track to provide a permanent record of the test sequence. A remotely-operated back-pressure valve was used to control the test section pressure. A high-pressure water quench was used to reduce the gas temperatures upstream of the valve to less than $700 \mathrm{~K}$ to prevent damage to $1 \mathrm{t}$. 


\section{Fuel Systems}

The fuel delivery system used in this program consisted of three subsystems (Fig. 9): a nitrogen purge system, a Jet A system, and a No. 6 fuel oil system. Jet A fuel, which was used for catalytic reactor startup, was supplied to the test cell from underground storage tanks by positive displacement pumps generating pressures up to $6 \mathrm{MPa}$. Gaseous nitrogen was available to purge fuel from the manifold and injection tubes when desired.

Drum quantities of the residual fuel were heated using electrical band heaters and a fuel agitation system to reduce the fuel viscosity to a value suitable for pumping (fuel temperature of approximately $320 \mathrm{~K}$ ). A gear pump was used to deliver the fuel to the test rig, a positive displacement flowmeter was employed to meter the flow. Included in the fuel delivery system was a resistance-type fuel heater capable of raising the fuel temperature to over $400 \mathrm{~K}$. This device was used to establish the fuel temperatures (and therefore the fuel viscosity) required for the desired degree of fuel atomization. The fuel system had a circulation leg originating downstream of the fuel heater to permit establishing the desired fuel flowrate and temperature prior to injecting it into the test rig. The residual fuel lines and manifold were heat traced and insulated to maintain the desired fuel temperature. Premixed fuel blends were also delivered using this batch fuel system.

\section{Instrument at ion}

The test rig was instrumented according to standard practices, the location of the parameters measured are indlcated in Fig. 10. The test section airflow was determined using an ASME venturi located upstream on the main air heater, it was sized to operate choked for all test conditions. Jet A fuel flow rates were determined using turbine flowmeters; a positive displacement flowmeter was used for the residual fuel. The conditions entering the test section (i.e., upstream of the fuel injector) were documented by radial arrays of three total pressure probes and three thermocouples, four wall static pressure measurements were also obtained at this position. Differential pressure transducers were used to document the pressure drop across both the entire test section and the catalytic reactor alone. An array of three, equally-spaced thermocouples ( 120 degrees apart, mid-radius) were located at the catalyt ic reactor exit to verify the spatial uniformity of the combustion process. Additional temperature measurements were made on the centerline $15 \mathrm{~cm}$ and $30 \mathrm{~cm}$ downstream of the reactor exit. The catalytic reactor was instrumented with six thermocouples embedded within dedicated channels of the substrate. Four of these measurements were made along the centerline; one additional measurement was made near the outer edge of the reactor at both the reactor inlet and exit. 
A water-cooled sampling probe was located on the centerline of the gas phase reactor elther $15 \mathrm{~cm}$ or $30 \mathrm{~cm}$ downstream of the reactor exit. The gas sampling probe was designed to achieve an aerodynamic quick-quench of the captured stream in order to minimize chemical reaction within the probe. Figure 11 depicts the features of the probe design and specifies the dimensions of the final configuration. The sample flow was captured at the tip and accelerated from a Mach number of unity to a high supersonic Mach number by the tip area expansion. This expansion was large enough to achieve the required reduction in static temperature to quench chemical reactions, yet not so large as to cause excessive frictional losses which would reduce the stagnation pressure below the pumping capacity of the sample system. The flow next entered a constant area section where the stagnation temperature was reduced by heat transfer. In this constant area portion, both the stagnation pressure and the supersonic Mach number of the flow were reduced because of friction. The constant area section was terminated prior to the onset of choking with a sudden expansion to stabilize a shock system which reduced the Mach number to a subsonic value. Several probe geometries were analyzed with an existing UTKC computer program to arrive at the final configuration. The probe analysis tracked the $C O$ concentration through the probe $t i p$, along the supersonic region, across the shock, and along the subsonic portion of the probe. Calculations indicated that reaction within the final design would result in less than a one unit change in a carbon monoxide emission index for the matrix of test conditions. The probe was constructed from three concentric stainless steel tubes, the sample passed in the central tube with the outer tubes providing the probe cooling path. It had a $0.95-\mathrm{cm}$ outer diameter with a $0.18-\mathrm{cm}$ diameter inlet orifice The shock stabilization point was $7 \mathrm{~cm}$ from the inlet.

The captured sample was transferred to the emission analysis system in an electrically-heated sample line. The system (Fig. 12) was capable of continuously monitoring the emissions of carbon monoxide, oxygen, carbon dioxide, unburned hydrocarbons and oxides of nitrogen. The signal output and attenuator position were automatically transferred to the data acquisition system. A listing of the instrument types, including ranges and accuracies, is given in Table 2 .

Data Acquisition and Reduction

The test conditions were established based upon values of key parameters displayed in the JBTS Control Room. Principle items monitored included: pressure upstream of the alrflow venturi, pressure and temperature at the test section inlet, pressure at the reactor inlet, pressure and temperature exiting the reactor, flowmeter output for both Jet $A$ and residual fuel, fuel temperature exiting fuel heater and pump, pressure and temperatures in the fuel manifold, pressure of the water coolant, and gas sample species concentrations. 
The complete set of test data was recorded by means of an automatic data acquisition system which recorded the stored information on magnet ic tape for subsequent computer processing. The data system accepted analog data on up to 25 channels, ten provided with signal conditioners and the remainder compatible with preconditioned inlet signals. The system was capable of controlling and accepting data from submultiplexers such as pressure and thermocouple scanning switches. The data channels were scanned sequentially at the rate of 12 channels per second and, whenever a submultiplexer was connected to a channel, all ports or stations were sampled before proceeding to the next channel. An analog-to-digital converter digitized the data and an incremental magnetic tape recorder stored it for subsequent computer processing. The format of the tape was structured for compatibility with the UTRC UNIVAC 1110 digital computer.

The recorded data were used to compute several parameters which characterized the test condition and results including:

Combustor inlet pressure, $P_{3}$

The combustor pressure was measured in the mixer/vaporizer immed lately upstream of the reactor.

Combustor inlet temperature; $\mathrm{T}_{3}$

The combustor inlet temperature was the arithmetic mean of the temperature measured by the three thermocouples located upstream of the fuel injector.

Airflow rate, $\mathrm{m}_{\mathrm{a}}$

The aurflow rate was calculated from the equation for choked flow through a venturi.

Reference velocity, uref

The reference velocity was determined from $m_{a}, P_{3} \cdot T_{3}$ and the $7.6-\mathrm{cm}$ diameter flow area.

Fuel flowrate, $\mathbf{m}_{\mathbf{f}}$

The fuel flowrate of either Jet $A$ or the test fuel was determined from the flow meter output frequency.

Fuel-air ratio, $f / a$

The fuel-air ratio was the quotient of $m_{a}$ and $m_{f}$. 
Emission Index, EI

The concentration of $\mathrm{CO}$, UHC, $\mathrm{NO}_{\mathrm{X}}, \mathrm{CO}_{2}$ and $\mathrm{O}_{2}$ were determined from the respective analyzer output and appropriate calibration curve. The emissions index for species 1 was calculated according to:

$$
E_{1}=10^{-3} \mathrm{PPM}_{1} \frac{\mathrm{MW}}{\mathrm{MW}} \frac{1+\mathrm{f} / \mathrm{a}}{\mathrm{f} / \mathrm{a}}
$$

where $P P M_{1}$ and $M W_{1}$ were the concentration and molecular weight of species 1 , and $M W$ was the molecular weight of product mix. The UHC concentration was analyzed as equivalent methane; the emission index of ${ }^{N O} x$ used the molecular we ight of $\mathrm{NO}_{2}$.

Emissions fuel-a1r ratio, f/a-em

A fuel-air ratio was calculated from the analyzed gas sample following the procedure presented by Spindt (Ref. 15). In this procedure the combustion reaction was represented as.

$$
\mathrm{C}_{\mathrm{x}} \mathrm{H}_{\mathrm{y}}+\alpha_{2}+\mathrm{ZN}_{2}+\mathrm{XCO}_{2}+\frac{\mathrm{y}}{2} \mathrm{H}_{2} \mathrm{O}+\mathrm{ZN}_{2}+\mathrm{BO}_{2}
$$

Spindt showed that the air to fuel ratio was determined by the expression:

$$
(\mathrm{f} / \mathrm{a})^{-1}=F_{b}\left[11.492 \mathrm{~F}_{\mathrm{c}} \times \frac{1+\mathrm{R} / 2+\mathrm{Q}}{1+\mathrm{R}}+\frac{120\left(1-\mathrm{F}_{\mathrm{c}}\right)}{3.5+\mathrm{R}}\right]
$$

where

$$
\begin{gathered}
\mathrm{F}_{\mathrm{b}} \equiv \frac{\mathrm{PPM}_{\mathrm{CO}}+\mathrm{PPM}_{\mathrm{CO}_{2}}}{\mathrm{PPM}_{\mathrm{CO}}+\mathrm{PPM}_{\mathrm{CO}}+\frac{\mathrm{PPM}_{\mathrm{CH}}}{12.011+1.008(\mathrm{y} / \mathrm{x})}} \\
\mathrm{R} \equiv \frac{12.011}{\mathrm{PPM}_{\mathrm{CO}}}{ }^{\mathrm{PPM}_{\mathrm{CO}}}
\end{gathered}
$$


R81-914724-18

$$
\mathrm{Q} \equiv \frac{\mathrm{PPM}_{2}}{\mathrm{PPM}^{\mathrm{CO}} \mathrm{O}_{2}}
$$

and

$$
\mathrm{P}_{\mathrm{CH}}=\frac{\mathrm{PPM}_{\mathrm{UHC}}}{1-\frac{9.008 \times \mathrm{Y}}{\mathrm{Mw}, \rho}}
$$

Combustor exit temperature, $\mathrm{T}_{4}$

The combustor exit temperature was the arithmetic mean of the temperature measured by three thermocouples located within $2 \mathrm{~cm}$ of the reactor exit.

Ideal exit temperature, $\mathrm{T}_{4}$, ideal

The ideal exit temperature was calculated from an enthalpy balance across the reactor using $\mathrm{P}_{3}, \mathrm{~T}_{3}$ and $\mathrm{f} / \mathrm{a}$.

Percent combustion efficiency, ETA

The reported combustion efficiency was determined from the $\mathrm{CO}$ and UHC calculated emissions indices and heating values (assuming the UHC heating value was equivdlent to the fuel heating value), and the emission index for the calculated equilibrium $C O$ concentration, according to:

$$
E T A=100\left\{1.0-10^{-3}\left[E I_{U H C}+0.232\left(E I_{C O}-E I_{C O}, \text { equilib }\right)\right]\right\}
$$


SECTION IV

TESTS RESULTS

Tests were performed to evaluate catalytic combustion of mixtures of residual fuel and air, and to determine the influences of incomplete fuel vaporization and the presence of droplets on the performance of the reactor. The ranges of the test parameters are indicated in Table 3. As will be discussed more fully below, it was necessary to expand the ranges of these parameters, the expanded limits are also shown on the Table. This section of the report presents test results under both the original and the expanded test conditions. The test results are divided into two sections: tests performed with No 6 residual fuel, and tests performed with blends of residual fuel and No 2 fuel 011 .

Performance with No. 6 Fuel 011

In the tests performed with No. 6 fuel oil, the residual fuel was not injected into a cold (i.e., non-operating) reactor. Rather, Jet A fuel was first injected from the multiple-venturi injector into the heated airflow required for the test condition. The startup fuel flow was increased unt 11 the combustor exit temperature was approximately $1400 \mathrm{~K}$. Simultaneously, the residual fuel was heated using the startup recirculation leg of the fuel system (see F1g. 9) to establish the desired fuel flow rate and fuel temperature. Once the reactor was stabilized on the startup fuel, the residual fuel was routed to the multiple venturi injector. The temperatures exiting the reactor were monitored, the residual fuel flow rate was increased and the Jet $A$ fuel flow decreased to mantain the exit temperature in the range of $1400 \mathrm{~K}$ to $1550 \mathrm{~K}$. Several schemes for this transition process were tried, attempting either to achieve a rapid, but unsteady, transistion or a slow multiple steady state transistion. None of these schemes was found to be totally satisfactory. While slow transistions were desirable to assess the ability of the reactor to combust a combination of Jet $A$ and residual fuels, they often placed unsatisfiable fuel control system demands for small changes, rapid transistions could potent ially result in undesirably high fuel-air ratio excursions. (Note: The quasi-steady approach was not identical to blending the fuels since the injection characteristics of the blend would differ from the characteristics of the indrvidual fuels.)

Stable catalytic combustion of the No. 6 oil was not achieved. Fifteen combinations of the test parameters (pressure, temperature, reference velocity, fuel temperature) were investigated as indicated in Table 4. Also included in the table are the calculated spray SMD and degree of vaporization at the reactor 
inlet. (Degree of vaporization was calculated using the multiple-component representation of the fuel.) Initially, the tests were performed at $0.6 \mathrm{MPa}$ and an air temperature of $600 \mathrm{~K}$, as this was the design condition for the test section. High fuel temperatures were used (up to $400 \mathrm{~K}$ ) to increase the atomization and subsequent vaporization of the fuel. The reactor was brought into a stesdy operating condition on Jet $A$ fuel as evidenced both by a uniformly bright exit plane as seen in the closed-circuit television system and by reactor exit temperature levels within three percent of the mean. As the No. 6 fuel was introduced, the exit plane of the reactor darkened, occasionally being high-lighted with intermittent bright zones; the thermocouples at the exit plane of the reactor showed significant spatial and temporal variations. These phenomena were accompanied by bursts of luminous particles exiting the reactor. The reactor exit plane became totally dark and an insignificant temperature rise existed across the reactor when half of the total fuel flow consisted of residual fuel. Similar phenomena were observed for tests performed with inlet temperatures up to $700 \mathrm{~K}$ at either $0.45 \mathrm{MPa}$ or $0.6 \mathrm{MPa}$. Half of the eight conditions with temperatures up to $700 \mathrm{~K}$ had calculated degrees of fuel vaporization of 50 percent or higher. Apparently this level of fuel vaporization was insufficient to sustain stable, catalytic combustion. In general, whenever the No. 6 oil was flowing condensed phase particles were observed exiting the reactor. These particles could have been either fuel droplets passing through the device or carbonaceous solids produced from droplet impingement on the reactor walls. The former explanation was not likely however as the droplets had a torturous path through the $25-\mathrm{cm}$ long reactor. Rather, it was felt that heavy, non-volatile components of the fuel were being deposited on the reactor walls where they carbonized and subsequently flaked-off into the gas path. Such a deposition would reduce the temperature of the large cell elements, reducing the surface reaction rates and thus destabilizing the reactor.

The activity of the reactor was diminished after each test with the residual oil as evidenced by the inability to satisfactorily react a subsequent flow of Jet A fuel. Either of two rejuvenation processes were followed to restore catalytic activity. Initially, rejuvenation was attained by flowing air at a temperature of $800 \mathrm{~K}$ through the reactor for approximately one hour. When successful, this period of exposure to hot air satisfactorily oxidized the remaining fuel deposits and restored the catalytic activity. It was discovered that this process could be accelerated to require only fifteen minutes if a flow of Jet $A$ fuel was introduced to produce an exit temperature of $1400 \mathrm{~K}$. Three copies of the reactor described in Section II were assembled. A new reactor would have been substituted for the test reactor if the emission levels for Jet $A$ operation after rejuvenation did not duplicate the initial levels. Substitution was not required and a single reactor was used for the tests at $600 \mathrm{~K}$ and $700 \mathrm{~K}$, it was rejuvenated approximately ten times. The reactor did not experience any major physical damage. Cracks were observed in the walls of the large cell elements presumably because of excessive thermal stress, however the substrate did not crumble while it was in the test section. The reactor was removed subsequent to these tests; the large cell elements collapsed when handled. 
The inability to sustain stable catalytic combustion was attributed to an insufficient level of fuel vaporization. Tests were performed with a fresh (i.e. unused) reactor at higher inlet air temperatures ( $750 \mathrm{~K}$ to $840 \mathrm{~K}$ ) and with smaller initial droplet diameters to achieve nearly 100 percent fuel vaporization. The conditions for these tests and the calculated degree of fuel vaporization are also included in Table 4.

Pre-ignition was encountered in the mixer/vaporizer for all tests performed at inlet temperatures up to $840 \mathrm{~K}$ once the No. 6 oil was introduced, pre-ignition did not occur during startup on Jet $A$ fuel at these conditions. The phenomenon was detected by two thermocouples which were installed with the sensor flush with the inner wall of the mixer/vaporizer duct. Prior to ignition, the thermocouple outputs indicated a temperature slightly less than the air preheat temperature. At the onset of ignition both outputs increased at a moderate rate (approximately $200 \mathrm{~K} / \mathrm{sec}$ ), not the rapid rate expected if a homogenous autolgnition had occurred. The output from the thermocouples measuring the reactor substrate temperature rose to the complete combustion temperature subsequent to the pre-ignition. Changes in test conditions to a reduced pressure and a high reference velocity (low residence time) were unsuccessful in preventing this phenomenon.

A review of both these ignition events and the experiences galned in other programs at UTRC led to the supposition that excessive fuel deposits on the mixer-vaporizer duct wall contributed to the ignition. That is, while complete vaporization of fuel was predicted at the reactor inlet, this level would not have been achieved unt 11 passing through approximately 70 percent of the mixer/vaporizer duct. Hence, wall deposition would be possible. The deposits would produce a fuel-air ratio gradient ranging from very fuel-rich on the wall to fuel-lean in the bulk airstream. The presence of near stoich 1ometric mixtures in the boundary layer would be condusive to flashback, particularly if combustor pressure perturbations momentarily stagnated the flow. Additionally, since the residence time of fuel traveling in the boundary layer would be longer than the residence $t$ ime of the fuel in the bulk alrstream, reactions leading to an autolgnition could be initrated; this situation would also be aggravated for stoichiometric mixtures.

Discussions with engineers at NASA (Ref. 16) revealed observations similar to those experienced in this program and which were diagnosed to be caused by fuel deposition. In particular, tests with a residual fuel were successfully conducted at NASA for air preheat levels of $1000 \mathrm{~K}$ while frequent pre-1gnitions were experienced at a $750 \mathrm{~K}$ preheat. These results suggest that at high temperatures the fuel was vaporized sufficiently to preclude significant deposition. At lower temperatures, liquid fuel impingement on the mixer-vaporizer duct was probably experienced, resulting in boundary layer mixture ratios which supported a pre-ignition mechanism. 
Tests were conducted in an attempt to minimize the deposition. The several tests performed followed either of two approaches--avoiding deposition by restricting the fuel injection near the walls or avoiding deposition by accelerating the rate of fuel vaporization.

In tests following the former approach, fuel was injected at only $s 1 x$ of the nineteen injection sites; no fuel was injected through the central or outer ring of venturi tubes. While the post test inspection did indicate a decrease in fuel deposition on the wall, a reduced tendency for a pre-ignition was not realized. Instead, an increased sensitivity was apparent as pre-ignition was regularly experienced during operation with Jet $A$ fuel. Apparently the near stolchiometric mixture at the six injection sites (compared to an equivalence rat io of 0.3 if fuel was injected equally in all ventur 1 tubes) was responsible for the worsened pre-ignition characteristics.

The second approach to minimizing fuel deposition relied upon achieving greater rates of fuel vaporization by further increasing the inlet air temperature. A change in test procedures and a re-evaluation of the air heater operational limit permitted achieving an inlet temperature of $895 \mathrm{~K}$. Initial tests were pertormed at a reference velocity of $40 \mathrm{~m} / \mathrm{s}$ to maximize fuel atomization. As before, complete vaporization was predicted, but with the highest alr temperature this level was predicted to occur in the shortest distance in the mixer/vaporizer. Stable, but very inefficlent, combustion of the No. 6 oll was attained. The combustion efficiency improved with increasing fuel-air ratio but was only approximately 75 percent for a fuel-air ratio of 0.028 . Tests were also performed at reference velocities down to $20 \mathrm{~m} / \mathrm{s}$ to increase the reactant residence time within the combustor. The lower velocities degraded the injector atomization (1.e., produced larger droplets), which apparently led to fuel deposition as pre-ignition was again experienced.

This observation pointed out a trade-off imposed by the fuel injector-namely, fine atomization required high air velocities which compromised the reactor by reducing the flow residence time. An independent control of atomizing air (1.e., a1r-assist) would have been desirable. This trade-off became a significant factor only because it was necessary to operate outside the design conditions. That $1 \mathrm{~s}$, the fuel preparation system was designed to produce a partially-vaporized mixture of No. 6 fuel oul and air over the original range of conditions indicated in Table 3. Tests performed within these limits did not achreve stable combustion. In an attempt to achreve vaporization levels above the 50 percent limit, subsequent tests were performed at conditions which were more severe than originally anticipated. As a consequence, unexpected limitations were encountered--either pre-ignition, atomization or vaporization limitations. Because of these limitations, it was decided to perform tests with blends of residual fuel and No. 2 fuel orl. 
As a consequence of the test results presented above, a series of tests was performed with blends of residual fuel and No. 2 fuel oll. The objective of these tests was to first determine a threshold concentration of the residual fuel blend which would result in acceptable performance (i.e., stable, highly efficient combustion without pre-iginition). Subsequently, tests were performed w1th No. 2 oil and the threshold blend in an attempt to assess the influence of incomplete fuel vaporization on the reactor performance. The fuel blends Investigated were mixtures of either No. 6 oil and No. 2 oil, or shale residual 011 and No. 2 o1!. The shale residual oil was used as a blending component because 1 ts final bolling point was lower than the final point for the No. 6 (petroleum) 011. Therefore, shale oll blends did not have the very non-volatile species that were in a No. 6 blend. Blends were prepared according to weight fraction of the residual fuel in increments of 10 percent, samples of each blend were obtained and analyzed for specific gravity, viscosity and distillation characteristics. Tests to screen the fuel blends to determine the threshold level were performed at a condition defined by: pressure $=0.6 \mathrm{MPa}$, temperature $=670 \mathrm{~K}$ and reference velocity $=20 \mathrm{~m} / \mathrm{s}$. Once the threshold level was determined, performance characterization tests were performed at a pressure of $06 \mathrm{MPa}$, temperature $=600 \mathrm{~K}$ and $670 \mathrm{~K}$, and reference velocity of $10 \mathrm{~m} / \mathrm{s}$ and 20 $\mathrm{m} / \mathrm{s}$. In general, the tests were performed without use of a startup fuel as $1 t$ was desirable to determine the blend composition which could be used directly. That is, 1t was desired to determine an acceptable fuel mixture such as might result from combining residual and distillate fuels in a large fuel tank. A startup fuel was used in some tests for blends above the threshold level to determine if alternative operating procedures could alter the level.

Tests were performed with blends of No. 6011 and No. 2 oil using another fresh reactor. The screening tests began with performance characterization of No. 2 oll alone and proceeded with blends containing higher concentrations of the residual fuel. Acceptable performance was attained for the No. 2 oil and a 20-percent No. 6/No. 2 blend, but no significant reaction was observed with the use of a 40-percent No. 6/No. 2 blend. Subsequent tests with 30-percent and 20-percent blends also yielded unsatisfactory performance--a result in direct conflict with previous tests. A subsequent test with No. 2 oil alone produced a level of performance similar to that originally obtained. Additional tests with a 20-percent blend again produced unacceptable performance. Periods of rejuvenation with hot air and with Jet $A$ did not affect these observations. It appeared that some component of the residual fuel was deposited on the catalytic surface which was not removed in the rejuvenation processes. The degraded reactor was apparently more sensitive to operation with residual oil blends than with Jet $A$ or No. 2 fuel distillates. That 1s, the reactor was sufficrently overdesigned for light distillate fuels to preclude detection of the degradation. Similar screening tests were performed with a longer reactor (see below) with blends using the shale oll as the blending component. An initial test with No. 2 oll alone was followed by tests using blends with increasing weight concentration 
of the shale orl. Acceptable performance was attained with a 20-percent shale oil while unstable operation was observed with a 45-percent blend. The performance of the 20-percent blend was re-attained in a subsequent test, suggesting that it was the high molecular weight components in the No. 6 (and not in the shale o11) which previously affected the reactor performance. Additionally, bursts of luminous particles were not observed in tests using shale oil blends while they were still present in tests with No. 6 blends.

The apparent effect of fuel deposition experienced in tests with No. 6 oil or blends of No. 6 oil and No. 2 oil suggest that complete vaporization of No. 6 oil must be attained to achieve stable reactor operation. Long residence $t$ ime vaporizers represent one approach to achieve, complete vaporization at the relatively low combustor inlet temperatures associated with standard gas turbine operation. Such devices would be impractically long, however, unless extremely small fuel droplets were produced by the fuel injector. Alternative techniques which raise the inlet temperature (e.g., regenerative heat transfer) or otherwise augment the vaporization process may be necessary. One technique of the latter type is currently being evaluated--namely, the catalytic gasifier (Ref. 17). In limited tests, this device has shown the potential to gasify (i.e., vaporize and reform) extremely rich mixtures (equivalence ratio from 6 to 10) without the formation of carbon. Sufficient fuel reformation may occur such that even if complete vaporization was not attained, the remaining components would be acceptable for reactor operation.

A new, longer catalytic reactor was constructed from elements identical to those used to construct the device used in the tests with No. 6 oil alone. It was a graded cell reactor with lengths of large and medium cell segments equal to the original reactor; the length of the small cell segment was increased to $20 \mathrm{~cm}$. The length of the gas phase reactor was $30 \mathrm{~cm}$. The viscosity for fuel blends containing up to 50 percent residual fuel was 10 cs or less at a temperature of $300 \mathrm{~K}$. Therefore, the calculated atomization (equation on page 5) was not sensitive to the available range of fuel viscosity (fuel temperature). Hence, for a given operating condition, the atomization and subsequent vaporization level was controlled by the reference velocity and the length of the mixer/vaporizer. Therefore to obtain differing levels of vaporization for equivalent operating conditions, tests were performed with the standard mixer/ vaporizer length $(18 \mathrm{~cm})$ and a shortened mixer/ vaporizer $(9 \mathrm{~cm})$.

Performance characterization tests were conducted with No. 2 oil and with 20-percent shale oil blends over the range of conditions indicated above, and with the two lengths of mixer/vaporizer. The essential results from the reactor performance characterization using No. 2 oil and a 20-percent shale oil/No. 2 oil blend are contanned in Figs. 13 through 19. These figures show combustion efficiency (percent) versus fuel-air ratio for various test conditions. In general, they display a plateau of high performance which decreases 
rapidly below a certain fuel-air rat 10. Th1s rapid decrease is assocrated with extinguishing the gas phase chemical reactions which are required to complete the burnout of the partially oxidized species and to ach reve high levels of combustion efficiency. Thus an important performance characteristic is the fuel-air ratio at which the rapid decline in performance begins-a breakpoint fuel-air ratio. The subsequent discussions will contrast the values of the breakpoint fuel-air ratio for comparative test conditions.

The reactor displayed the characteristic response to changing reference velocity (F1g. 13), that is, for higher reference velocities the breakpoint fuel-air ratio had a higher value. At higher reference velocities the residence time within the reactor was diminished, permitting insufficient time to achieve the gas temperature rise required to initiate the homogeneous reactions. As expected, the reactor performance improved with increased air preheat (Fig. 14). The breakpoint fuel-air rat 10 was reduced for higher inlet temperatures because of enhanced catalytic reactivity at the elevated temperature.

Results from tests to discern the influence of the degree of fuel vaporization on a reactor fired with No. 2 oil are contained in Fig. 15. The calculated degree of vaporization (DOV) depended on the air preheat level and the length of the mixer/vaporizer $\left(\mathrm{L}_{\mathrm{MV}}\right)$. Calculations indicated that two of the data sets (circle and triangle symbols in Fig. 15) achieved equal levels of vaporization despite the differing mixer/vaporizer length. The performance for these two was essentially equivalent. The remaining two data sets in Fig. 15 represent different degrees of vaporization for the same operating condition because of differing mixer/vaporizer lengths. The standard performance signature was obtained for tests with the longer mixer/vaporizer, while for the shorter mixer/vaporizer, and associated lower degree of vaporization, a very poor performance characteristic was obtained (the temperature rise across the combustor indicated a combustion efficiency of approximately 80 percent). These results indicated an extreme sensitivity to the degree of fuel vaporiza$t$ ion for the $600 \mathrm{~K}$ level of air preheat. This sensitivity could not be investigated at elevated air temperatures because complete vaporization was expected at the $670 \mathrm{~K}$ preheat level.

Not all tests performed to isolate the influence of the degree of vaporization were consistent, however. Figure 16 depicts the results for tests in whch equivalent degrees of vaporization were expected to be obtalned for the same test condition despite differing mixer/vaporizer lengths, equivalent performance was not obtained. These results suggested that the conditions at the reactor inlet were not equivalent for the two tests. The degree of vaporization prediction may have been optimistic, and less than complete vaporization may have been achieved in the shorter mixer/vaporizer. It is also possible that, for the shortened mixer/vaporizer test, the fuel and air were incompletely mixed to a degree that resulted in degraded reactor performance. This effect would be accentuated for the conditions shown in Fig. 16 as compared to those of Fig. 15 because of the higher reference velocity. Without a direct determination of the actual degree of vaporization it is not possible to fully explain the observed performances. 
The reactor displayed the expected performance dependence on reference velocity when using the 20-percent shale oil blend (F1g. 17). Again, lower values of the breakpoint fuel-air rat 10 were obtained for the low reference velocity which provided longer residence time with in the reactor. The influence of degree of vaporization for the reactor using the shale oil blend is shown in Fig. 18. Two data sets (circle and diamond symbols) correspond to equivalent vaporization levels for the same operating condition; equivalent performance was obtanned. Two of the data sets correspond to differing levels of fuel vaporization achieved by using differing mixer/vaporizer lengths. The higher breakpoint fuel-air ratio was obtained with decreased fuel vaporization because a reduced gas phase fuel-air ratio was unable to maintain a sufficiently hot catalytic surface.

A comparison of the reactor performance for the three fuels tested cannot be made because results from equivalent test conditions were not obtalned. Test results did show that better performance was obtained with No. 2 oil than with No. 6/No. 2 blends (Fig. 19). Qualitative impressions formed during tests performed with shale oil blends were that they were more reactive than No. 6 oil blends; the shale blends did not result in pre-ignition nor did they produce a stream of luminous particles exiting the reactor. It would be expected that a high performance level could be achieved (i.e., low breakpoint fuel-alr ratio) for a reactor designed to operate with this fuel (e.g., improved catalyst formulation, longer reactor).

The measured concentrations of $\mathrm{UHC}, \mathrm{CO}, \mathrm{CO}, 02$, and $\mathrm{NOX}$ in the exhaust gas are tabulated in the Appendix. The expected findings of increasing $\mathrm{CO}$ and UHC with decreasing efficiency, the abundance of $\mathrm{CO}$ as compared to $\mathrm{UHC}$ and, for reactors fired on No. 2 oil, the low level of NoX were evident. The level of NOX emissions increased for tests using the 20-percent shale oil blend fuel because of the 0.46 wt percent $N$ in the shale oil. Complete conversion of this nitrogen to NOX would have resulted in EINOX $=3.0$ for the blend. The observed levels indicated a 50 to 60 percent conversion for these tests. 


\section{SECTION $V$}

CONCLUSIONS

The objective of the experimental program was to demonstrate efficient catalytic combustion of fuel-lean mixtures of residual fuel and air and to assess the influence of incomplete fuel vaporization on the performance of a catalytic reactor. Tests were primarily conducted with a No. 6 residual fuel; some tests were performed with No. 2 oll or blends of residual fuel and No. 2 011. Based upon test results in this program the following conclusions may be formed.

Stable catalytic reactor operation will not be achieved with incompletelyvaporized No. 6 oil. This characteristic was observed even for at tempts to burn blends of No. 6011 in No. 2 oll. In all cases, luminous particles, presumably the result of fuel deposition on the substrate, were observed exiting the reactor. System limitations precluded testing with fully vaporized No. 6 fuel because the conditions to achreve this level were significantly outside the original design envelope (efficient catalytic combustion of No. 6 orl has been obtained by other investigators (Ref. 16) if sufficient air preheat was used to assure complete vaporization). Therefore, fuel preparation devices which use techniques to achieve complete vaporization (e.g., regenerative heat transfer, catalytic gasifier) of the fuel need to be employed to sustain stable reactor operation

Stable reactor operation can be achieved with fuel blends which contain incompletely-vaporized shale residual o1l. Tests with shale oil blend did not lead to the catalytic reactor degradation experienced with No. 6 oil blends. It was concluded that the absence of the non-volatile, high-molecular weight components from the shale oll precluded lasting fuel contamination.

A significant performance degradation can exist for incomplete fuel vaporization. Significant performance degradation was obtained for 80 percent vaporızed No. 2 oil or 90 percent vaporized shale oil blends. 


\section{REFERENCE S}

1. Kesselring, J. P. et. al: Design Criteria for Stationary Source Catalytic Combustion Systems. EPA-600/7-7.9-181, August 1979.

2. Anderson, D. N.. Performance and Emissions of a Catalytic Reactor with Propane, Diesel and Jet A Fuels. NASA TM-73786, September 1977.

3. Tacina, R. R.: Experimental Evaluation of Premıxıng-Prevaporızing Fuel Injection Concepts for a Gas Turbine Catalytic Combustor. NASA TM-73755, 1977.

4 Tacina, R. R.: Experimental Evaluation of Fuel Preparation Systems for an Automotive Gas Turbine Catalytic Combustor, NASA TM-78856, 1977.

5. McVey, J. B. and J B. Kennedy: Lean Stability Augmentation Study. NASA CR-159536, May 1979 .

6. Ingebo, R. D. and H. H. Foster: Drop-Size Distribution for Crosscurrent Breakup of Liquid Jets in Airstreams. NACA TN 4087, October 1957.

7. Jasuja, A. K.: Atomization of Crude and Residual Fuel Oils. Journal of Engineering for Power, Vol, Pp., 250-258, April 1979.

8. Lorenzetto, G. E and A. H. Lefebvre Measurements of Drop Size on a Plain Jet Arrblast Atomizer. AIAA J., Vol. 15, No. 7, July 1977.

9. Rizkalla, A. A and A. H. Lefebvre: The Influence of Air and Liquid Properties on Airblast Atomization. Transactions of the ASME, Journal of Fluids Engineering, September 1975.

10. Cox, E. R. . Pressure-Temperature Chart for Hydrocarbon Vapors, Industrial and Engineering Chemistry, Vol. 15, No. 6, pp. 592-593, 1923.

11. Longwell, J. P. and M. A. Weiss: Mixing and Distribution of Liquids in High Velocity Air Streams. Industrial and Chemical Engineering, Vol. 45, 1953.

12. Chu, E. Catalytic Reactor Design for Combustion of Partially Vaporized No. 6 Fuel Oil. Acurex Project 7543 Report, 1979.

13. Pogson, J. T. and M. N. Mansour: No. 6 Fuel Oil Catalyt 1c Combustion. Third Workshop on Catalytic Combustion, Asheville, NC, October 1978. 


\section{REFE RENCES (Cont 'd)}

14. Kesselring, J. P. et. al: Kecent Advances in Catalytic Combustion System Development. ASME Paper 79-WA/Fu-8, December 1979.

15. Spindt, R. S.. Arr-Fuel Ratios from Exhaust Gas Analysis. SAE Paper 650507, May 1965.

16. Anderson, D. N. and D. Bulzan: NASA Lewis Research Center, personal communication.

17. Szetela, E. J., R. A. Sederquist, and J. A. TeVelde: Gasification of a Heavy and a Distillate Fuel. Proceedings Fourth Workshop on Catalytic Combustion, Cincinnati, OH. EPA-600/9-80-035, pp. 516-526, August 1980. 
TABLE 1

Fuel Properties

\begin{tabular}{|c|c|c|c|c|c|}
\hline \multicolumn{3}{|c|}{ H content (wt. pct.) } & 11.0 & 12.95 & 12.69 \\
\hline \multicolumn{3}{|c|}{$N$ content (wt. pct.) } & 0.15 & & 0.46 \\
\hline \multicolumn{3}{|c|}{ Heat of combustion $(j / g)$} & 42550 & 42570 & 42410 \\
\hline \multicolumn{3}{|c|}{ Aromatic content (vol. pct.) } & 62.4 & 34.5 & \\
\hline \multirow[t]{4}{*}{ Density $(g / c c)$} & $289 \mathrm{~K}$ & & & 0.853 & \\
\hline & $311 \mathrm{~K}$ & & 0.933 & & 0.863 \\
\hline & $339 \mathrm{~K}$ & & 0.899 & & \\
\hline & $367 \mathrm{~K}$ & & 0.871 & & \\
\hline \multirow[t]{3}{*}{ Surface tension } & (dyne/cm) & $311 \mathrm{~K}$ & 29.9 & & \\
\hline & & $339 K$ & 27.2 & & \\
\hline & & $367 \mathrm{~K}$ & 25.9 & & \\
\hline \multirow[t]{3}{*}{ Viscosity (cs) } & $311 \mathrm{~K}$ & & 632 & 2.79 & 12.8 \\
\hline & $339 \mathrm{~K}$ & & 101.6 & & \\
\hline & $372 \mathrm{~K}$ & & 25.5 & & 3.77 \\
\hline \multirow[t]{12}{*}{ Distillation ( $K)$} & IBP & & & 455 & 5.22 \\
\hline & 5 & & 528 & & \\
\hline & 10 & & 562 & 491 & 598 \\
\hline & 20 & · & 658 & 503 & 618 \\
\hline & 30 & & 714 & 515 & 637 \\
\hline & 40 & & 758 & 527 & 655 \\
\hline & 50 & & 772 & 539 & 670 \\
\hline & 60 & & 797 & 549 & 683 \\
\hline & 70 & & & 560 & 698 \\
\hline & 80 & & & 573 & 714 \\
\hline & 90 & & & 591 & 726 \\
\hline & EP & & & 622 & 730 \\
\hline Residue (pct.) & & & 40 & 1.5 & 6.0 \\
\hline
\end{tabular}


TABLE 2

Emissions Analysis Instrumentation

Component

THC

$\mathrm{NO}_{\mathrm{x}}$

$\mathrm{CO}$

$\mathrm{CO}_{2}$

$\mathrm{O}_{2}$

\section{Range}

0-1 ppmv

Intermediate ranges

$0-10 \%$

0-2.5 ppmv

Intermed iate ranges (6)

0-10,000 ppmv

0-100 ppmv

$0-500,0-1000$ ppmv

$0-5 \%, 0-10 \%$

$0-2 \%$

$0-5 \%$

$0-15 \%$

$0-1 \%$

$0-5 \%$

$0-10 \%$

$0-25 \%$
Instrument and Detection Method

Flame Ionization Detector

$\pm 1.0 \%$

$\pm 1.0 \%$

Chemiluminescence Detector

TECO Mode 1 10A

$\pm 1.0 \%$

$\pm 1.0 \%$

$\pm 1.0 \%$

Nond ispersive Infrared

Beckman Model 315B

$\pm 2.0 \%$

$\pm 1.0 \%$

$\pm 1.0 \%$

Nond Ispersive Infrared

Beckman Model 315B

$\pm 1.0 \%$

$\pm 1.0 \%$

$\pm 1.0 \%$

Paramagnet ic Analyzer

Scott Model 150 $\pm 1.0 \%$

$\pm 1.0 \%$

$\pm 1.0 \%$

$\pm 1.0 \%$ 
$R 81-914724-18$

\section{TABLE 3}

Test Parameter Ranges

\section{Parameter}

Reactor inlet pressure

Reactor inlet temperature

Keference velocity

Fuel-air ratio

Fue 1

\section{Original}

$0.6-0.9 \mathrm{MPa}$

$500-600 K$

$10-30 \mathrm{~m} / \mathrm{s}$

$0.016-0.026$

No. 6

\section{Expanded}

$0.3-0.6 \mathrm{MPa}$

$600-900 \mathrm{~K}$

$13-40 \mathrm{~m} / \mathrm{s}$

$0.016-0.028$

No. 6 , No. 2 , Blends 
TABLE 4

Conditions for No. 6 oil Tests

$$
\frac{\mathrm{P}_{3}}{\mathrm{MPa}}
$$

$\frac{\mathrm{T}_{3}}{\mathrm{~K}}$

$\frac{U_{\text {ref }}}{\mathrm{m} / \mathrm{s}}$

$\frac{\mathrm{T}_{\text {fue } 1}}{\mathrm{~K}}$

$\frac{\text { SMD }}{\text { microns }}$

$\frac{\text { Deg. of Vap. }}{\text { pct }}$

1. 0.3

780

40

370

20

90

2.

840

20

405

20

100

3.

840

25

416

17

100

4.

895

38

405

13

100

5. $\quad 0.45$

600

13

356

50

25

6.

700

14

353

55

35

7

700

14

381

30

60

8.

0.6

600

22

378

23

35

9.

600

29

389

16

40

10.

670

20

369

28

55

11.

670

20

389

21

65

12.

670

31

400

14

50

13.

755

20

394

21

95

14.

755

30

367

25

75

15.

783

20

372

27

90 


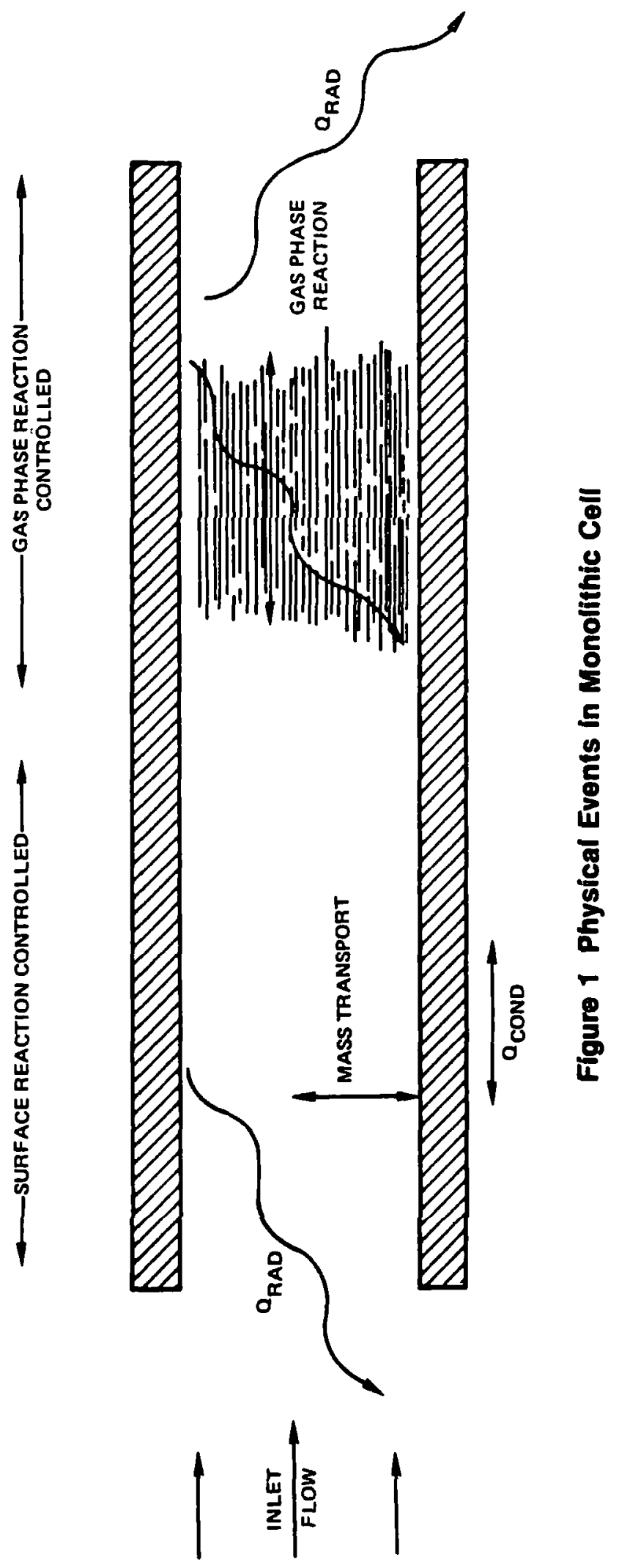




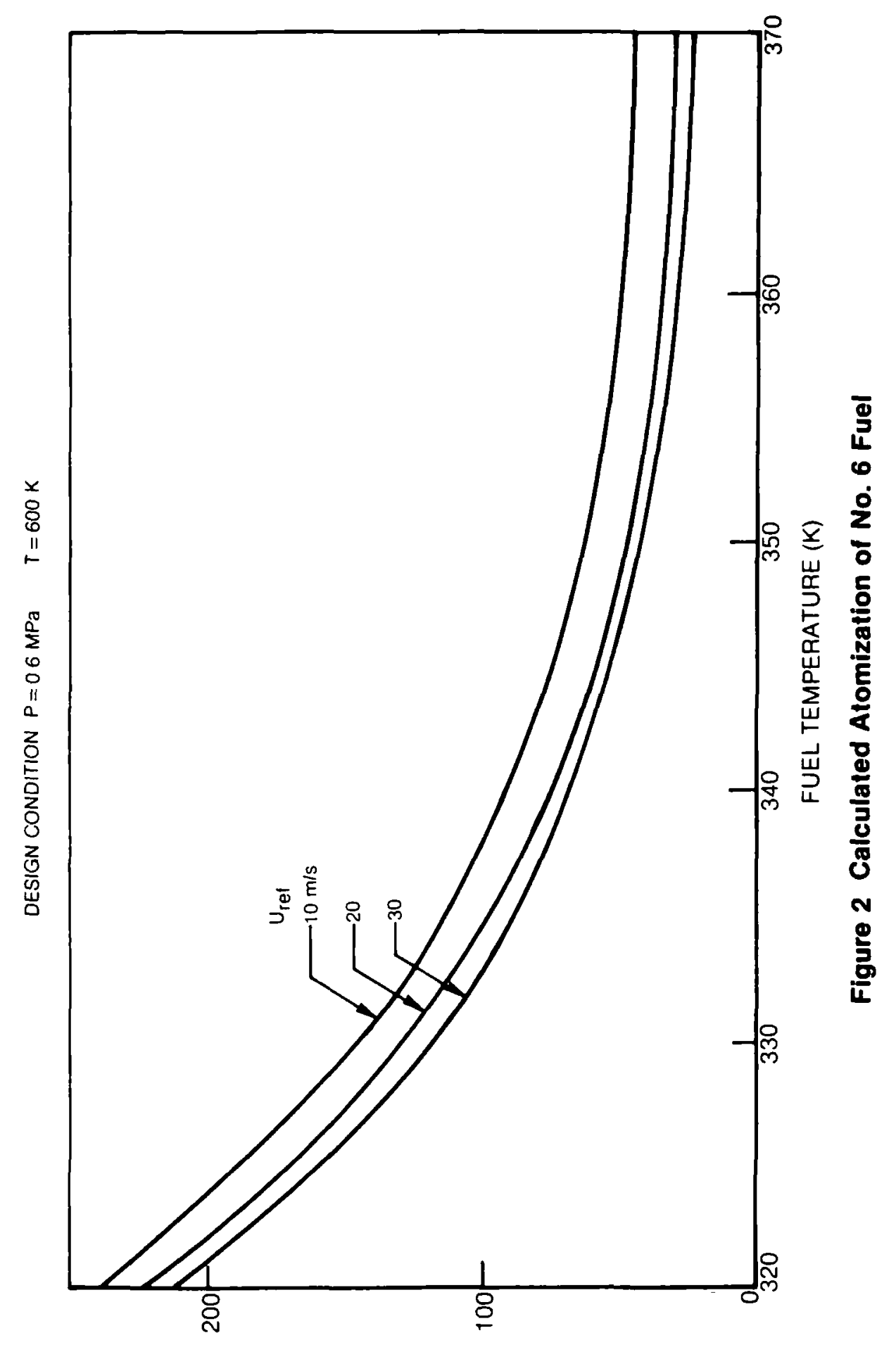

(suosom) aws 


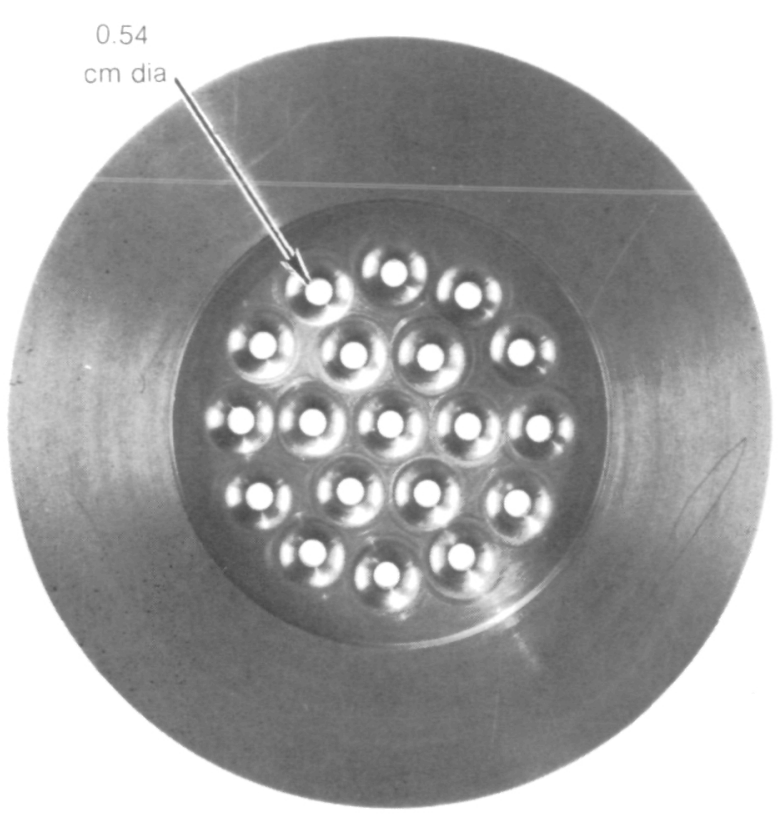

a) VIEW FROM UPSTREAM

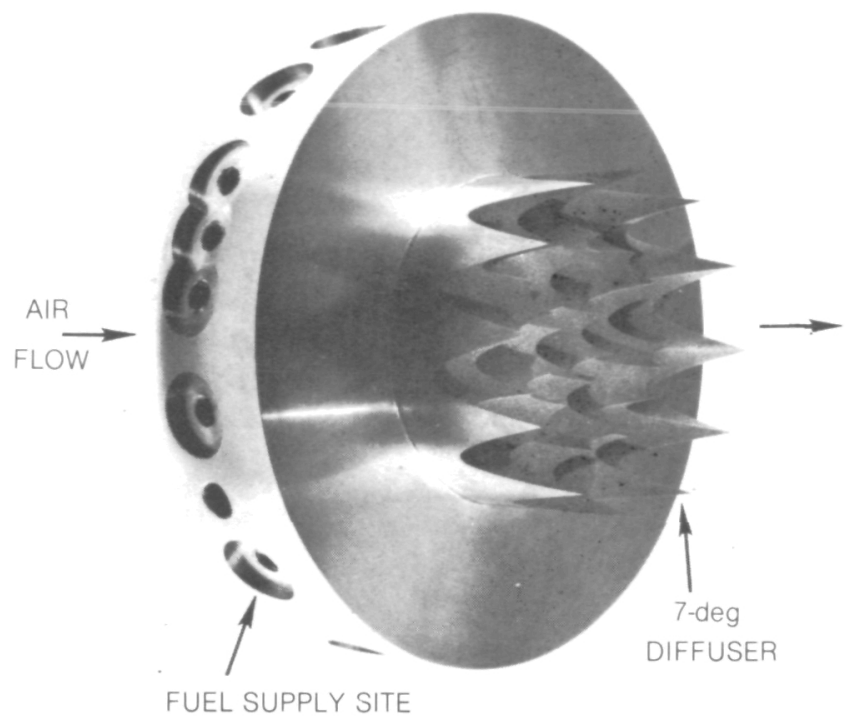

b) VIEW FROM DOWNSTREAM

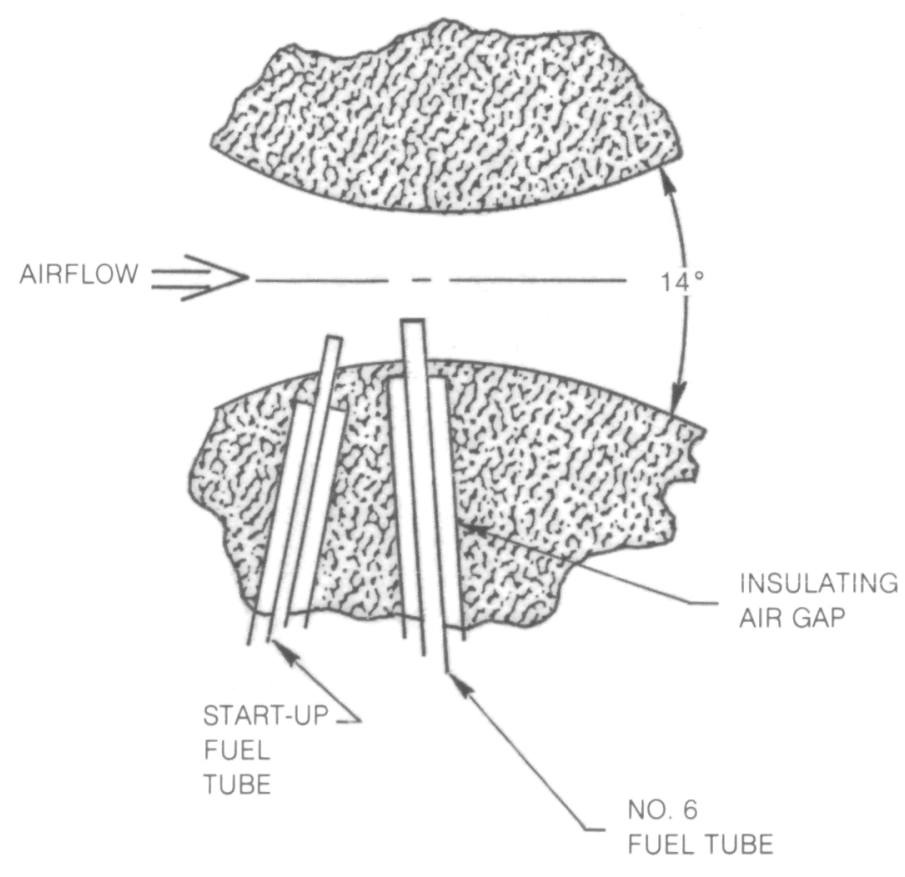

c) TYPICAL VENTURI THROAT

Figure 3 Multiple Venturi Fuel Injector 


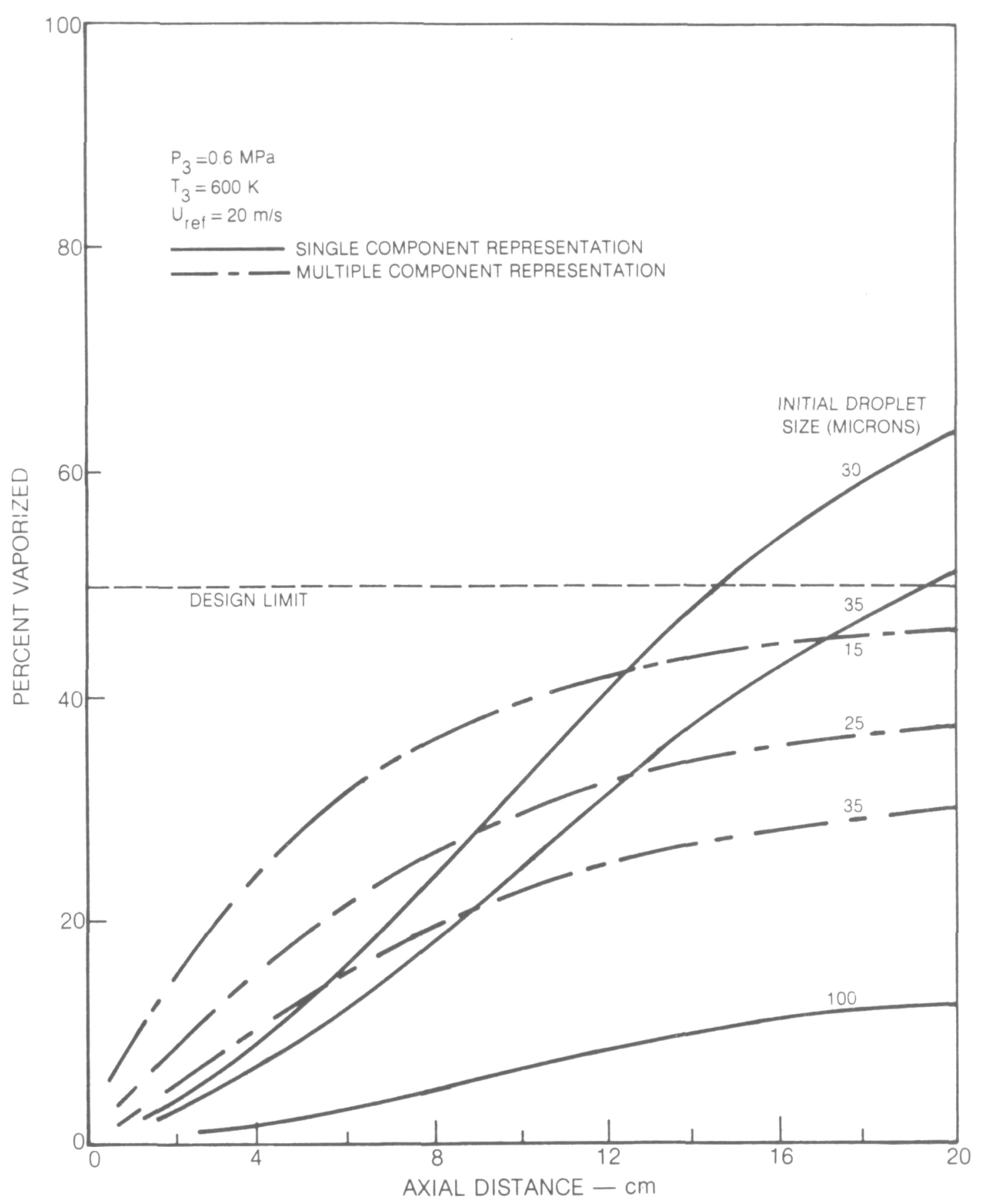

Figure 4 No. 6 Fuel Oil Droplet Evaporation Characteristics 


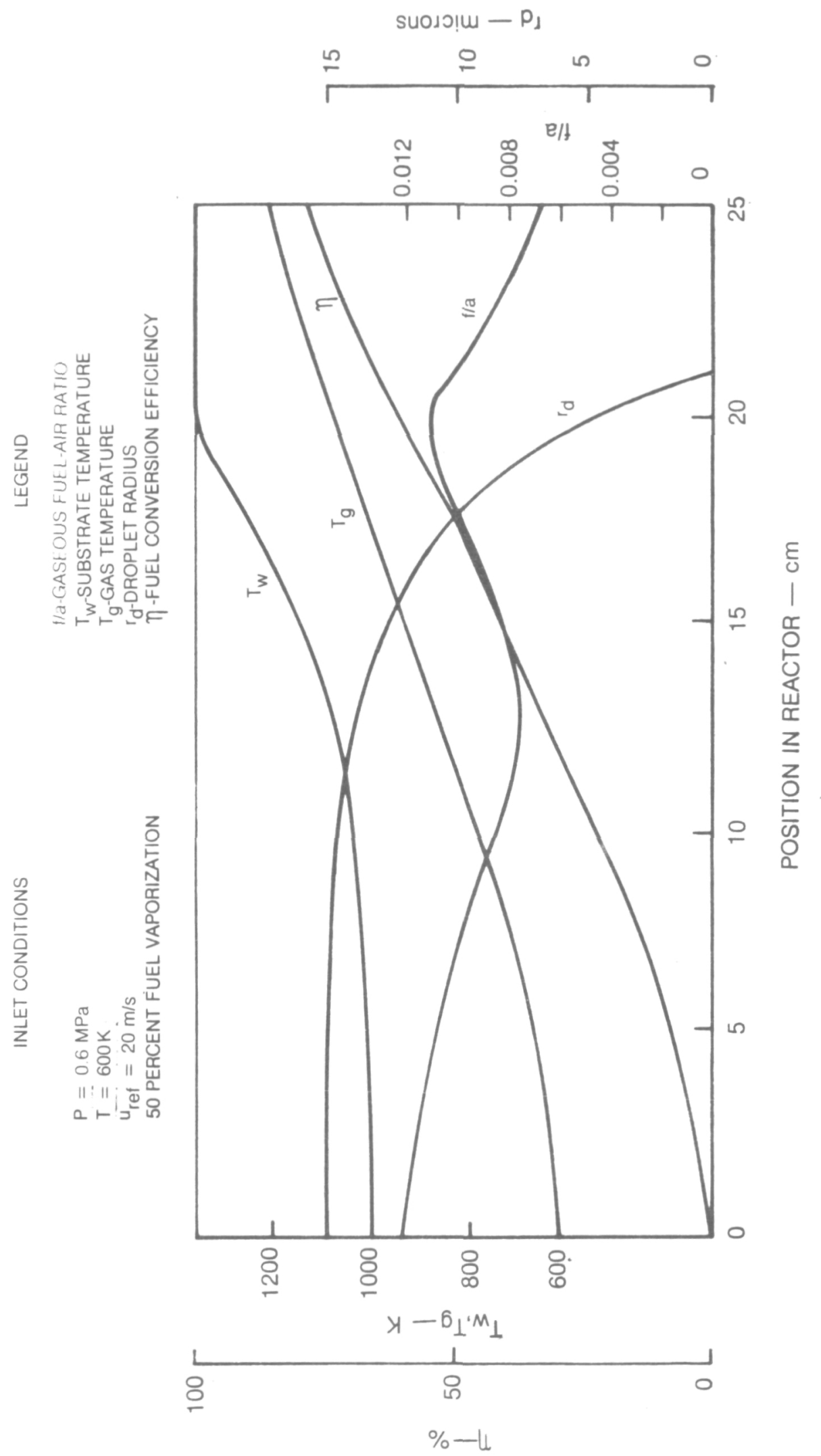

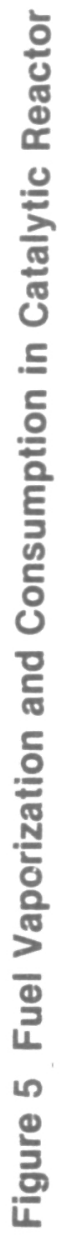




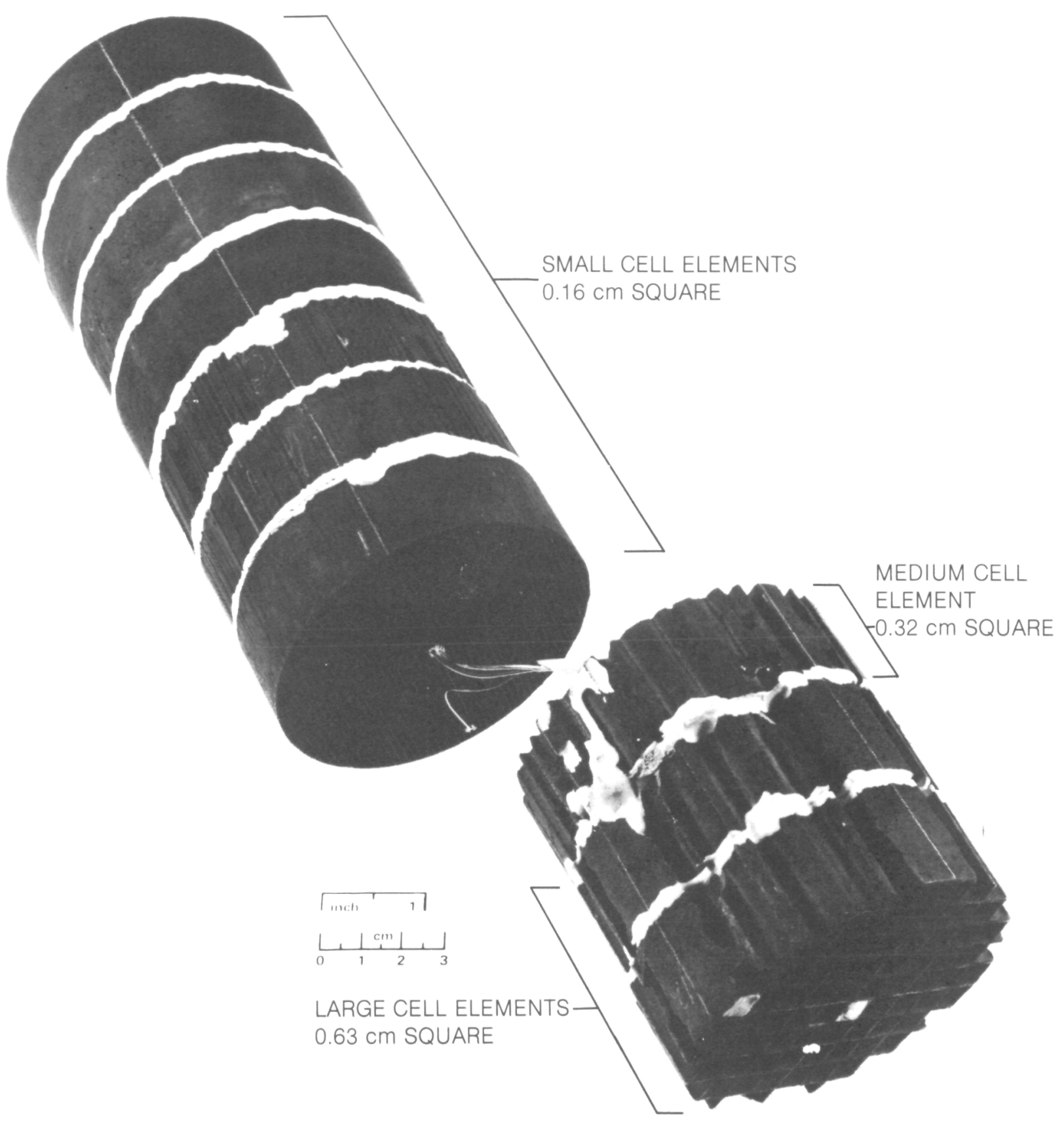

Figure 6 Graded Cell Catalytic Reactor 


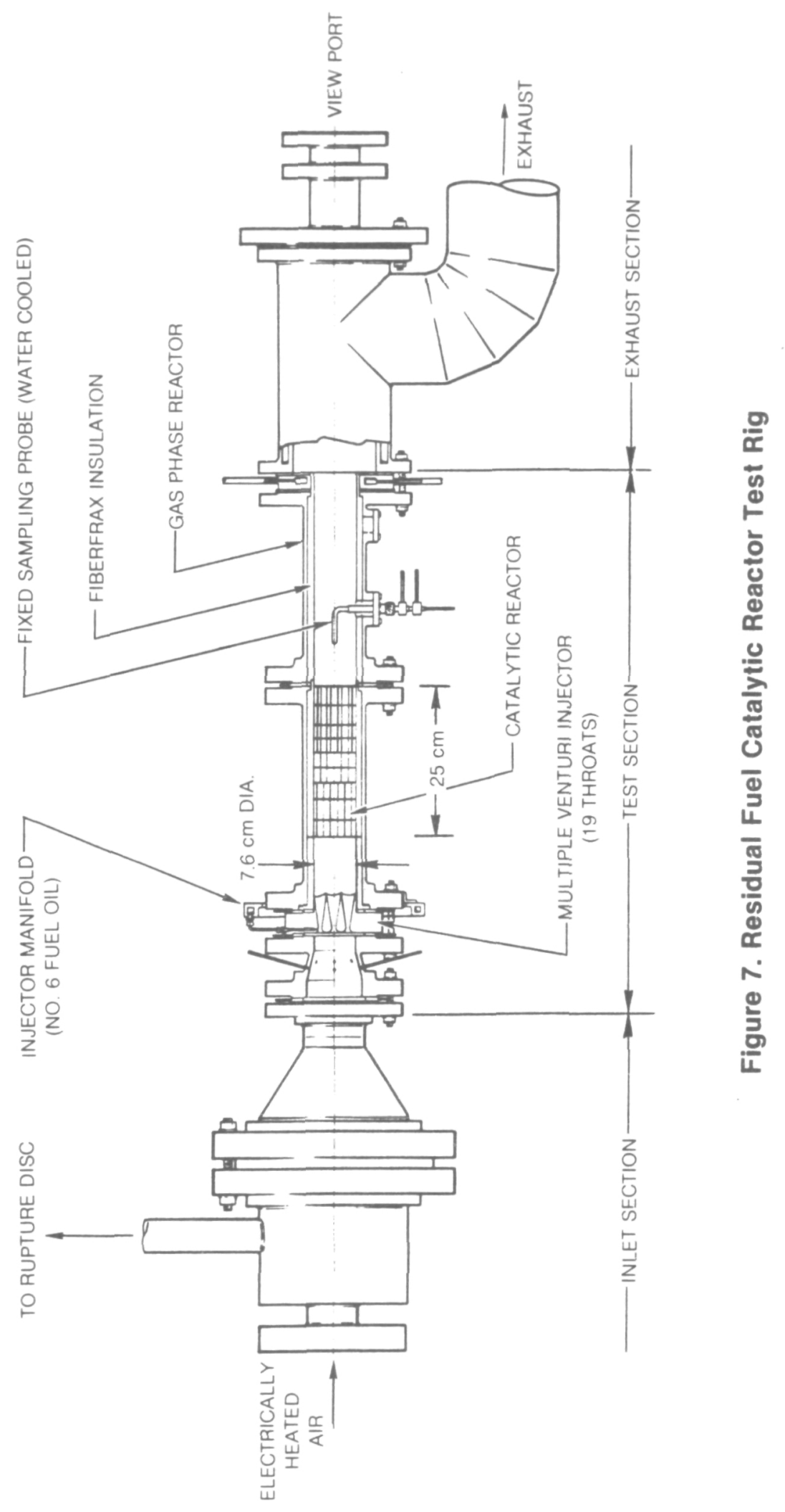




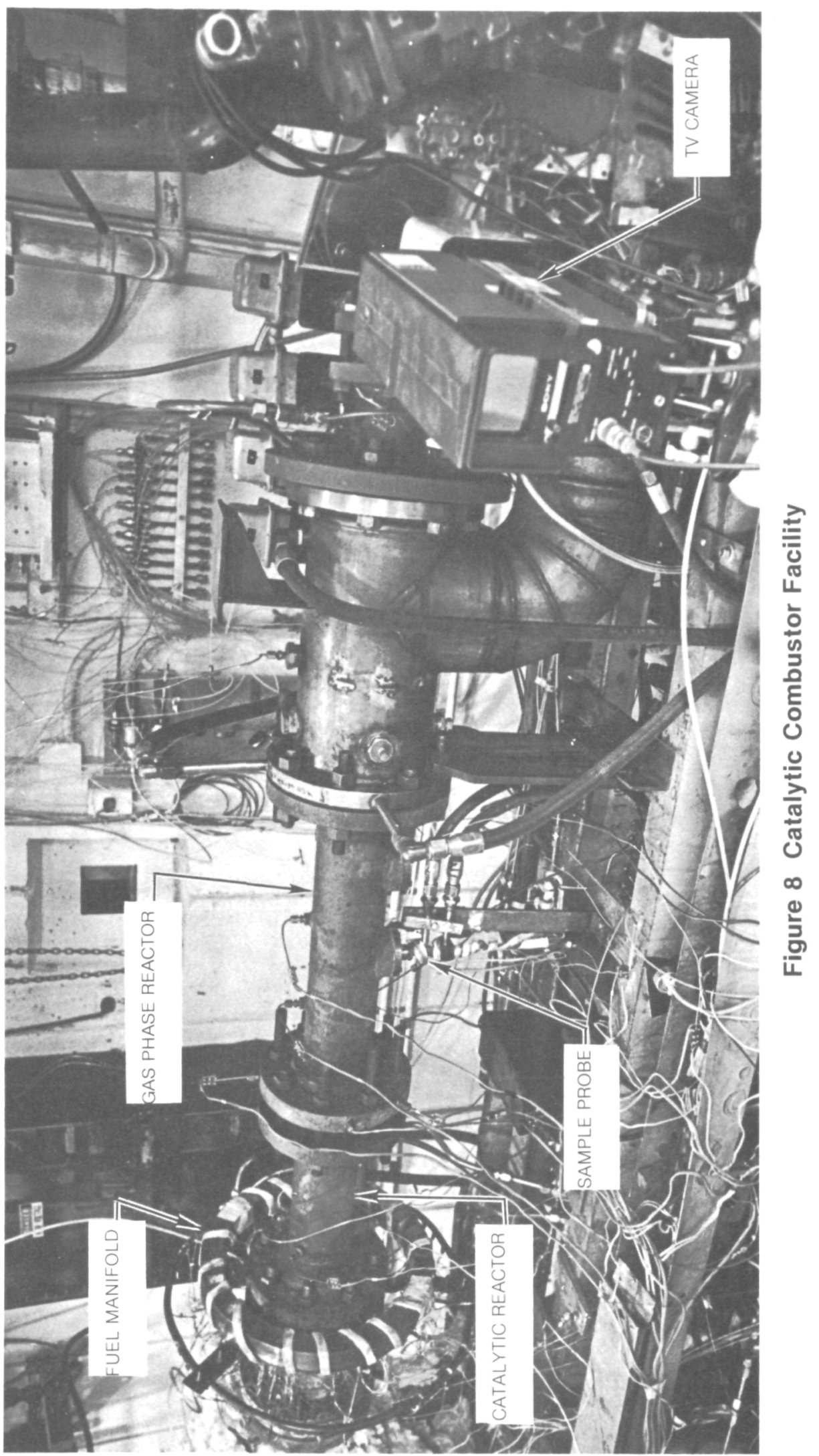




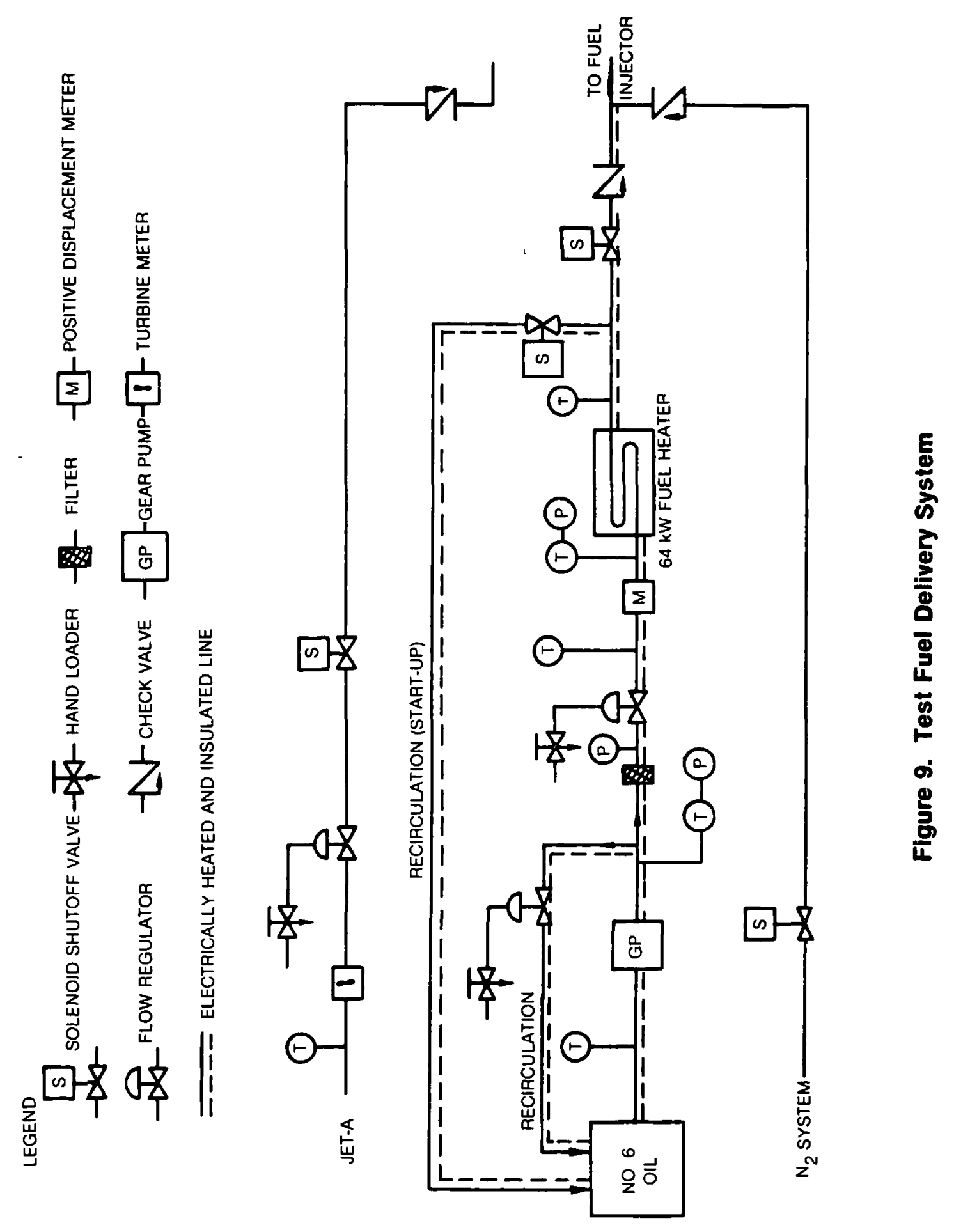




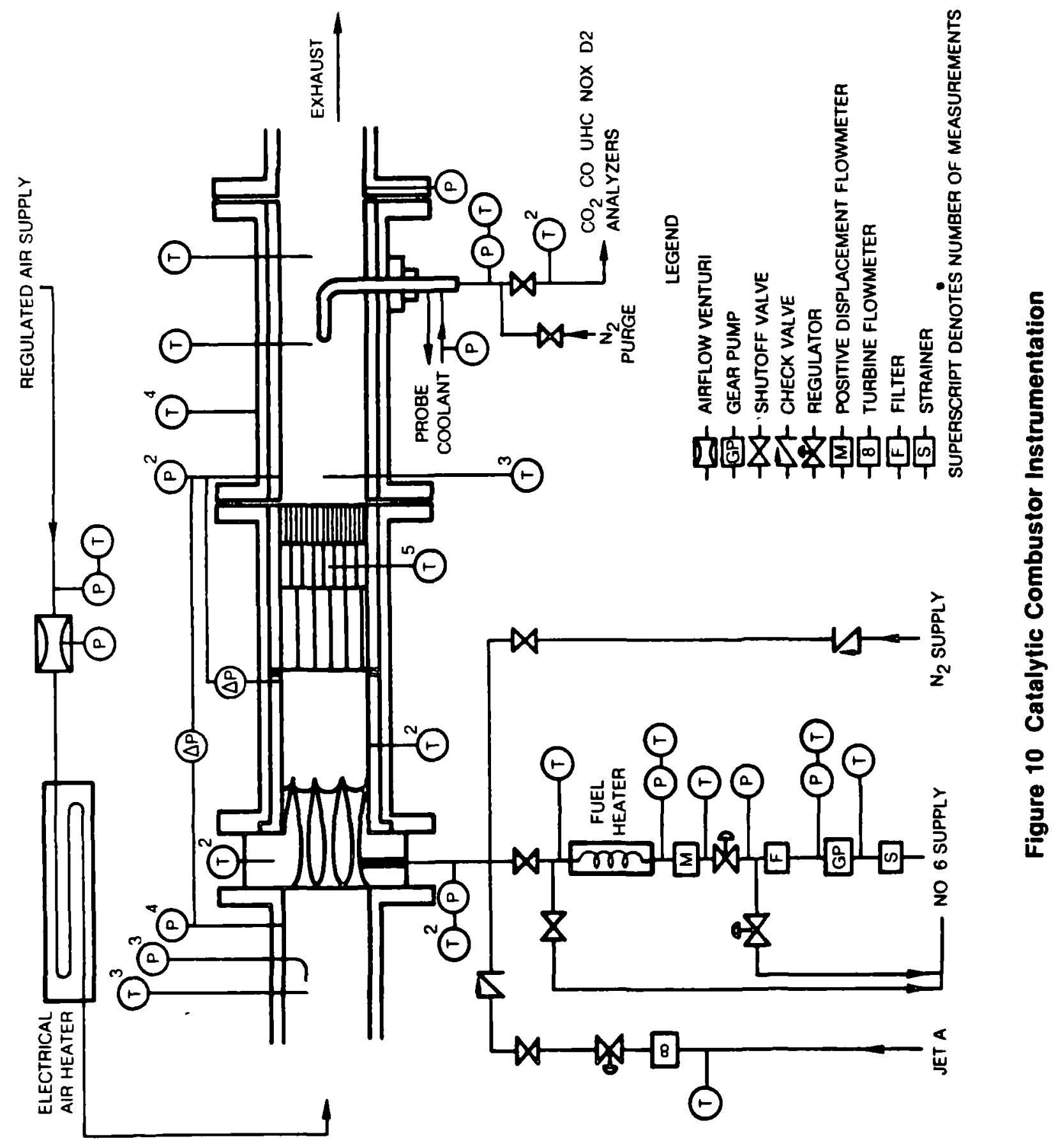




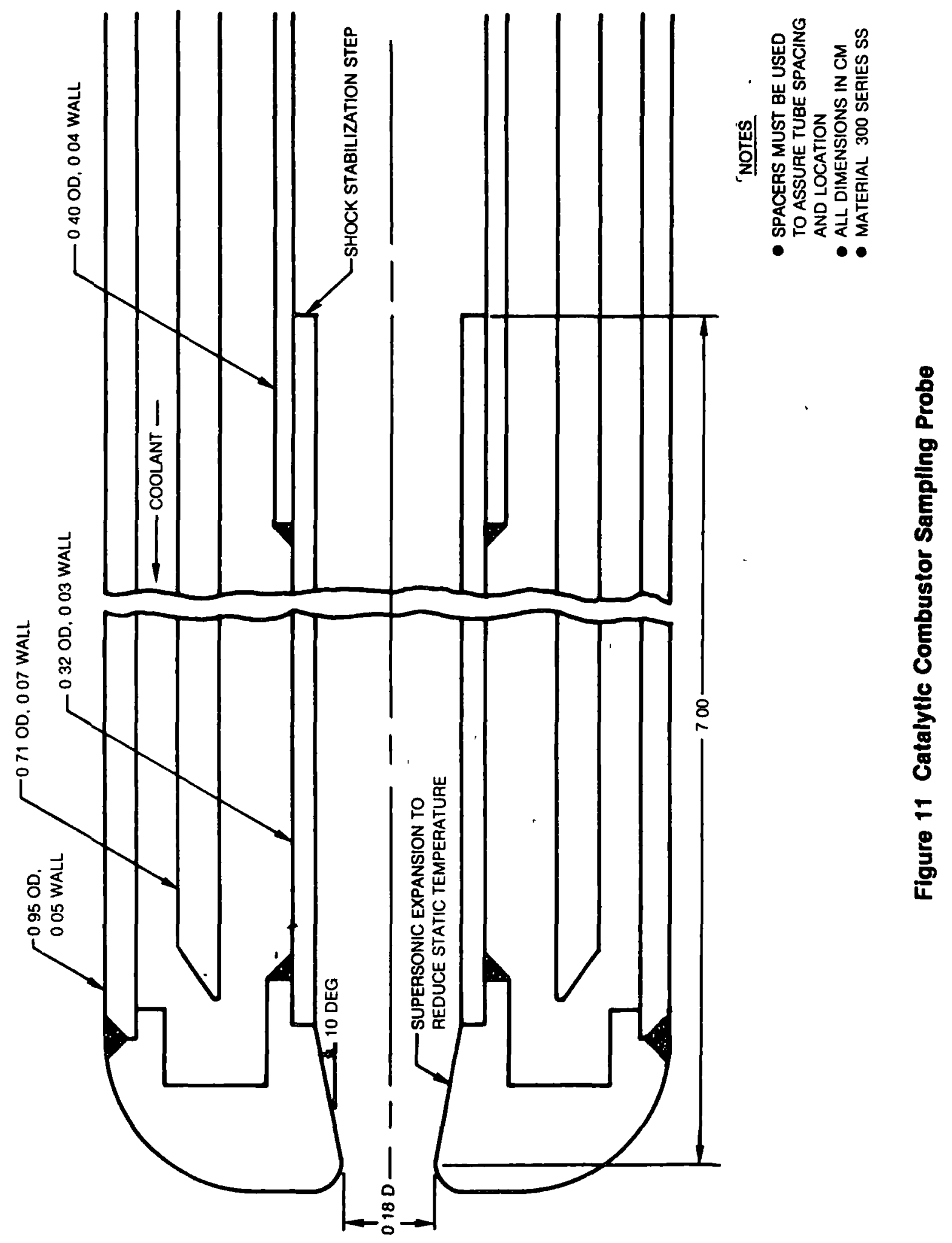




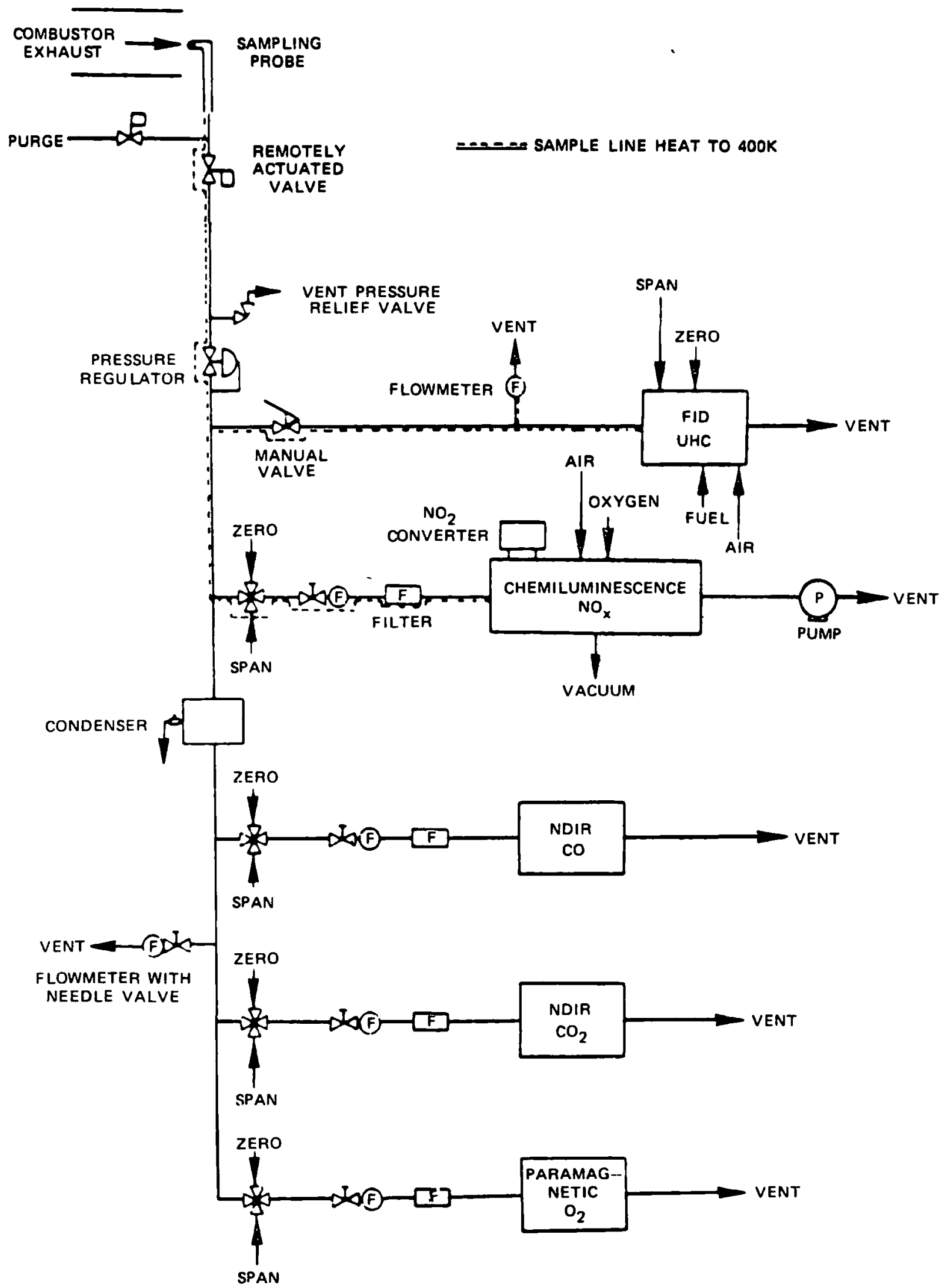

Figure 12 Emission Sampling and Analysis System 


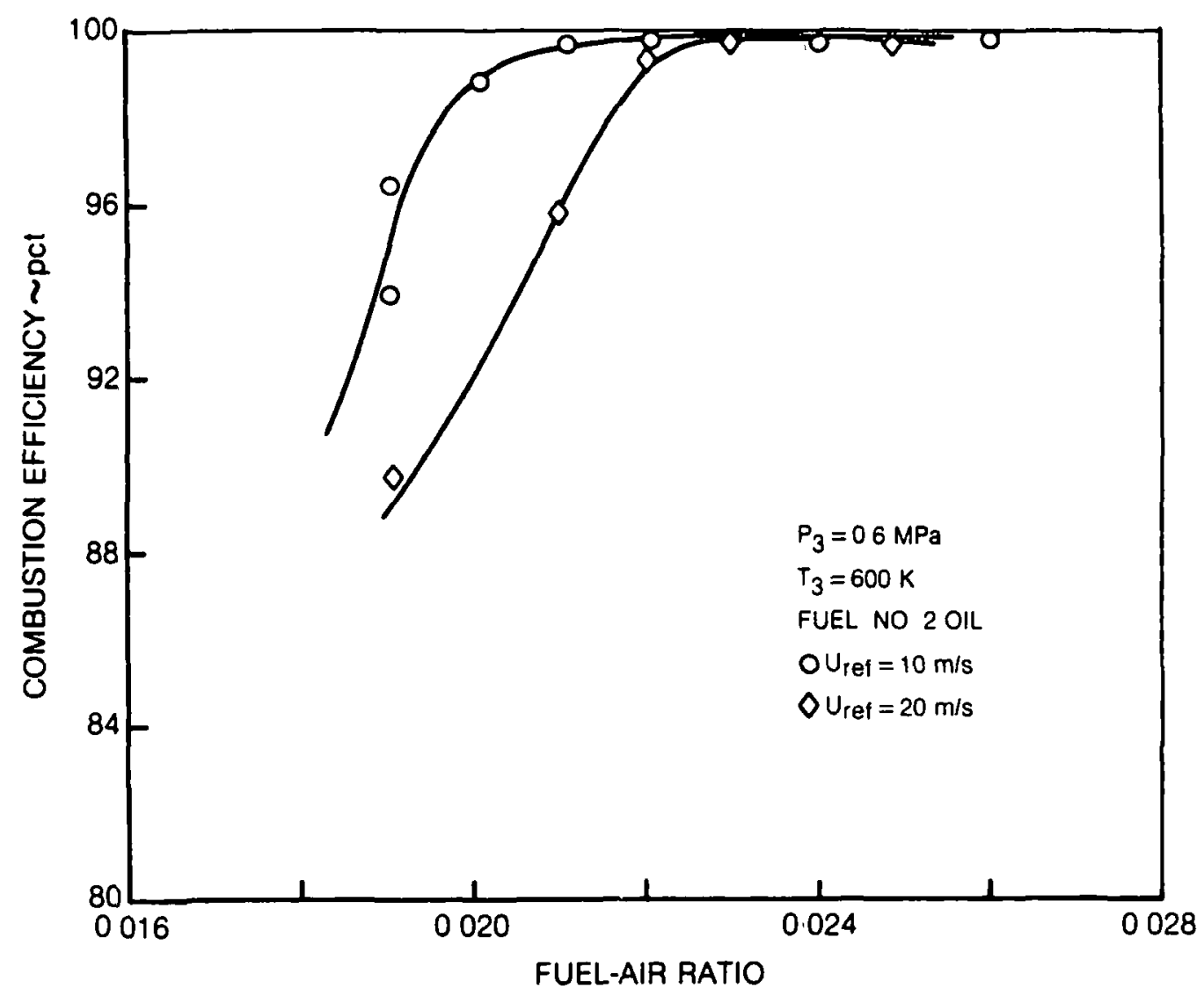

of

Figure 13 Reactor Performance With No. 2 Oil - Dependence on Reference Velocity 


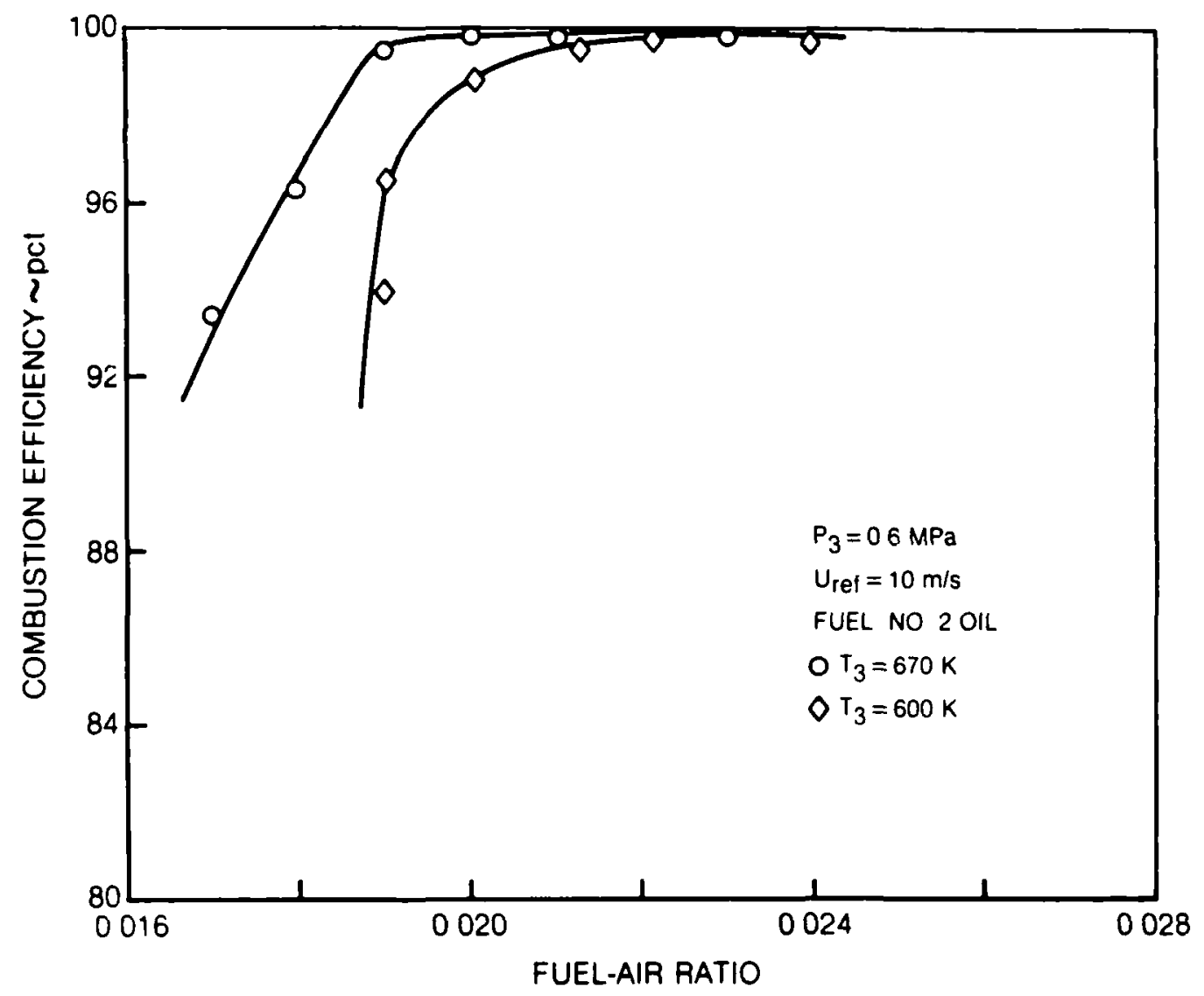

Figure 14 Reactor Performance With No. 2 Oll - Dependence on Alr Preheat 


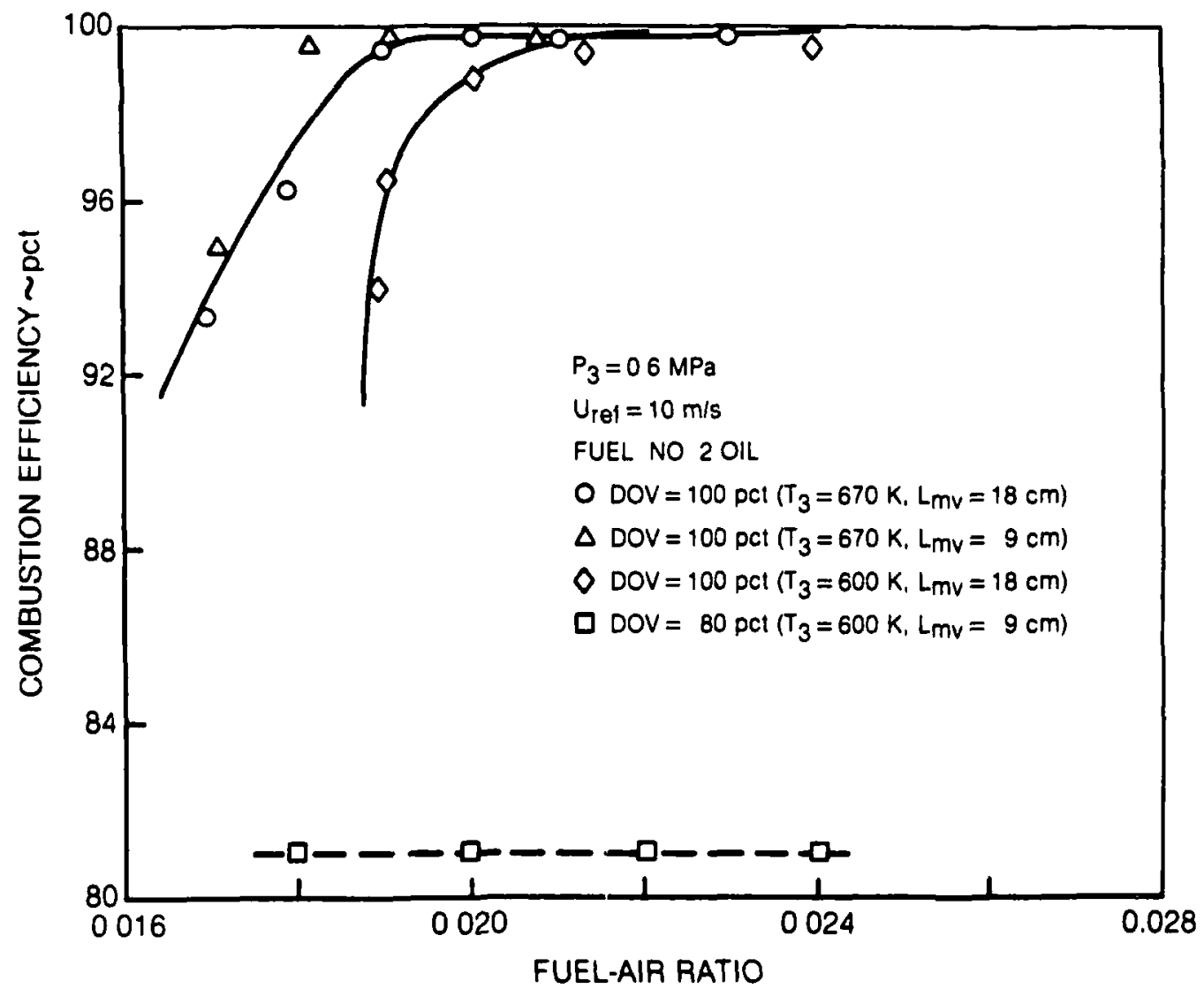

Figure 15 Influence of Degree of Vaporization on Reactor Performance Using No. 2 Oll 


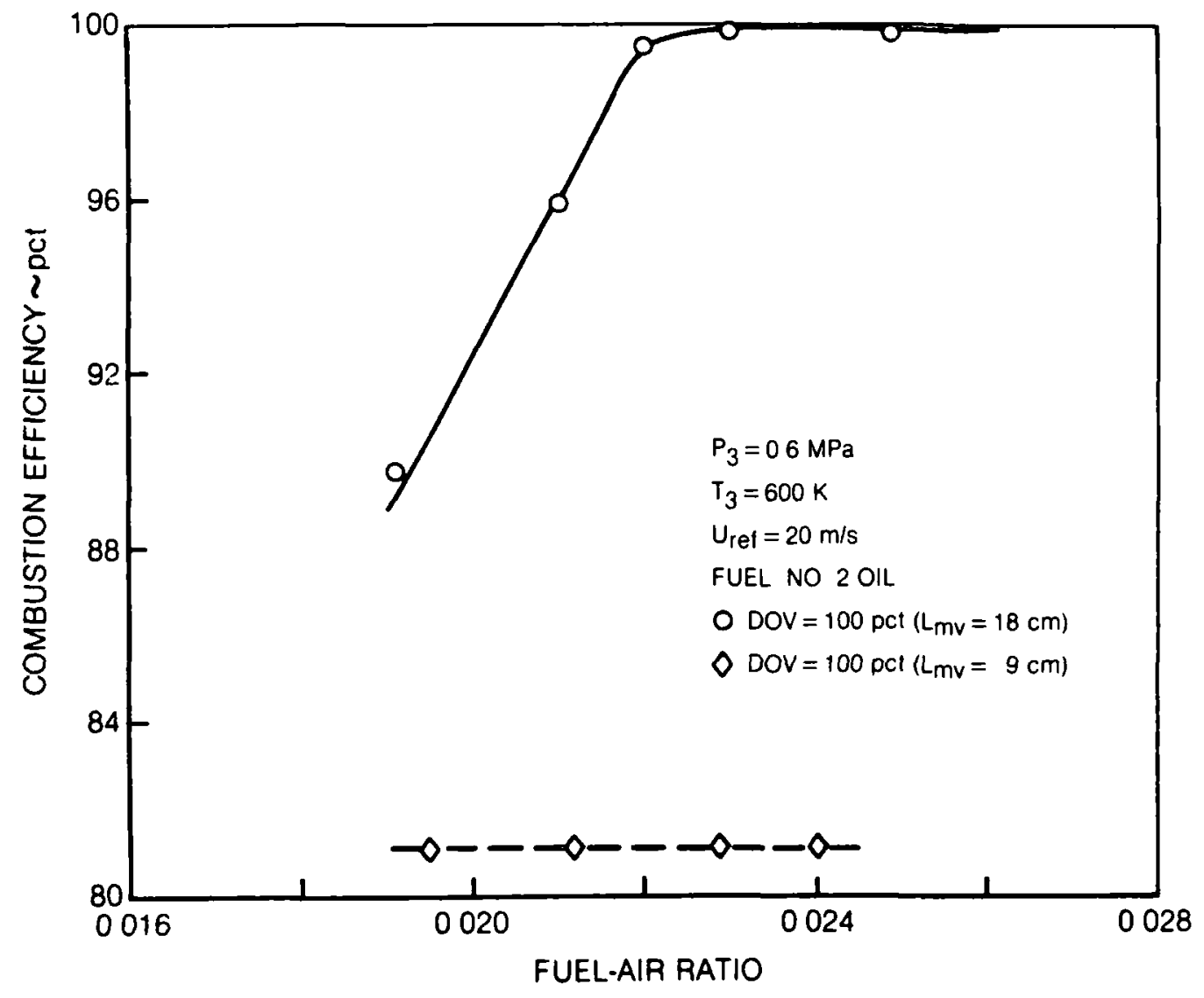

Figure 16 Inconsistent Reactor Performance Dependence on Degree of Vaporization 


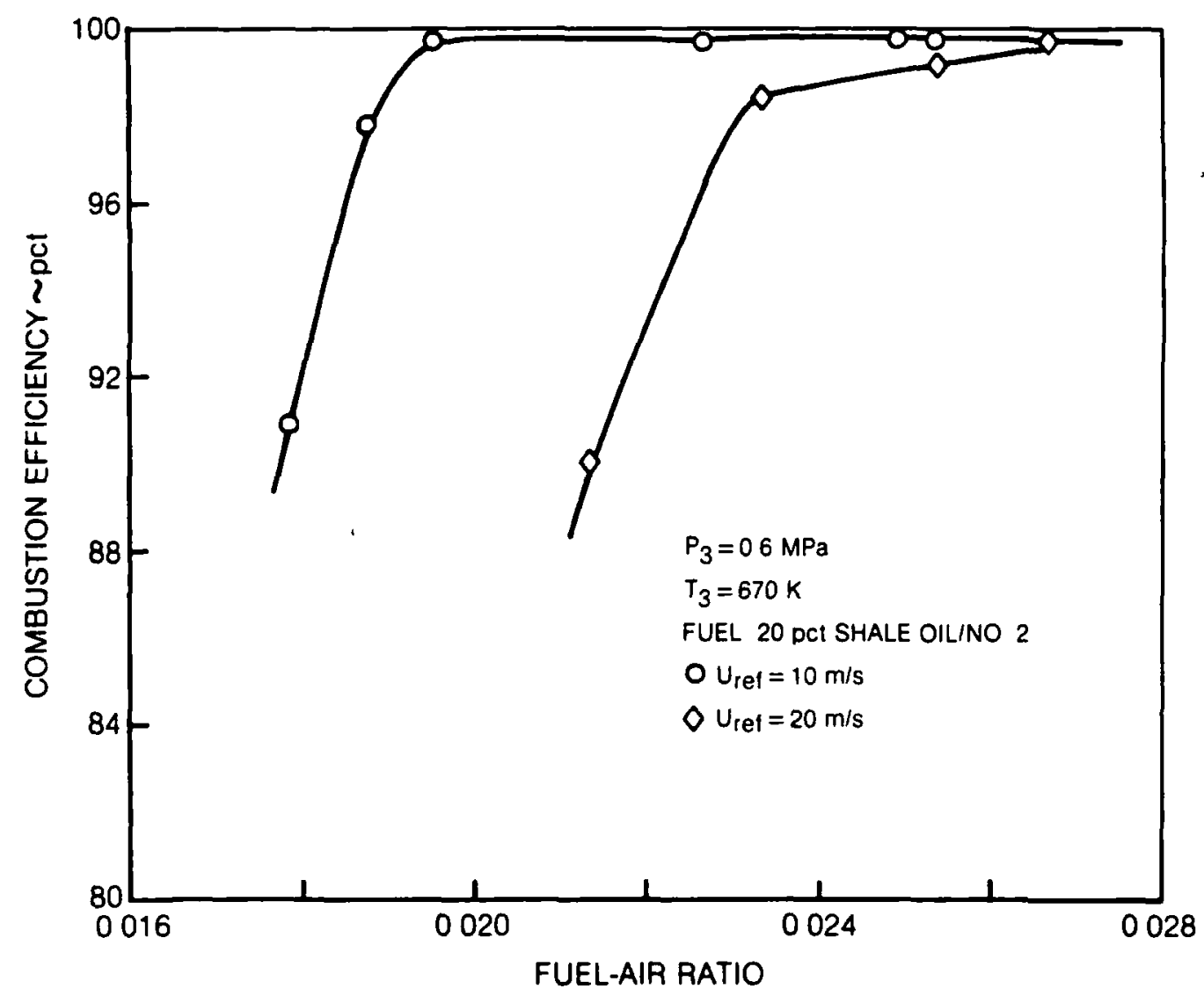

Figure 17 Reactor Performance With Shale Oil Blend - Dependence on Reference Velocity 


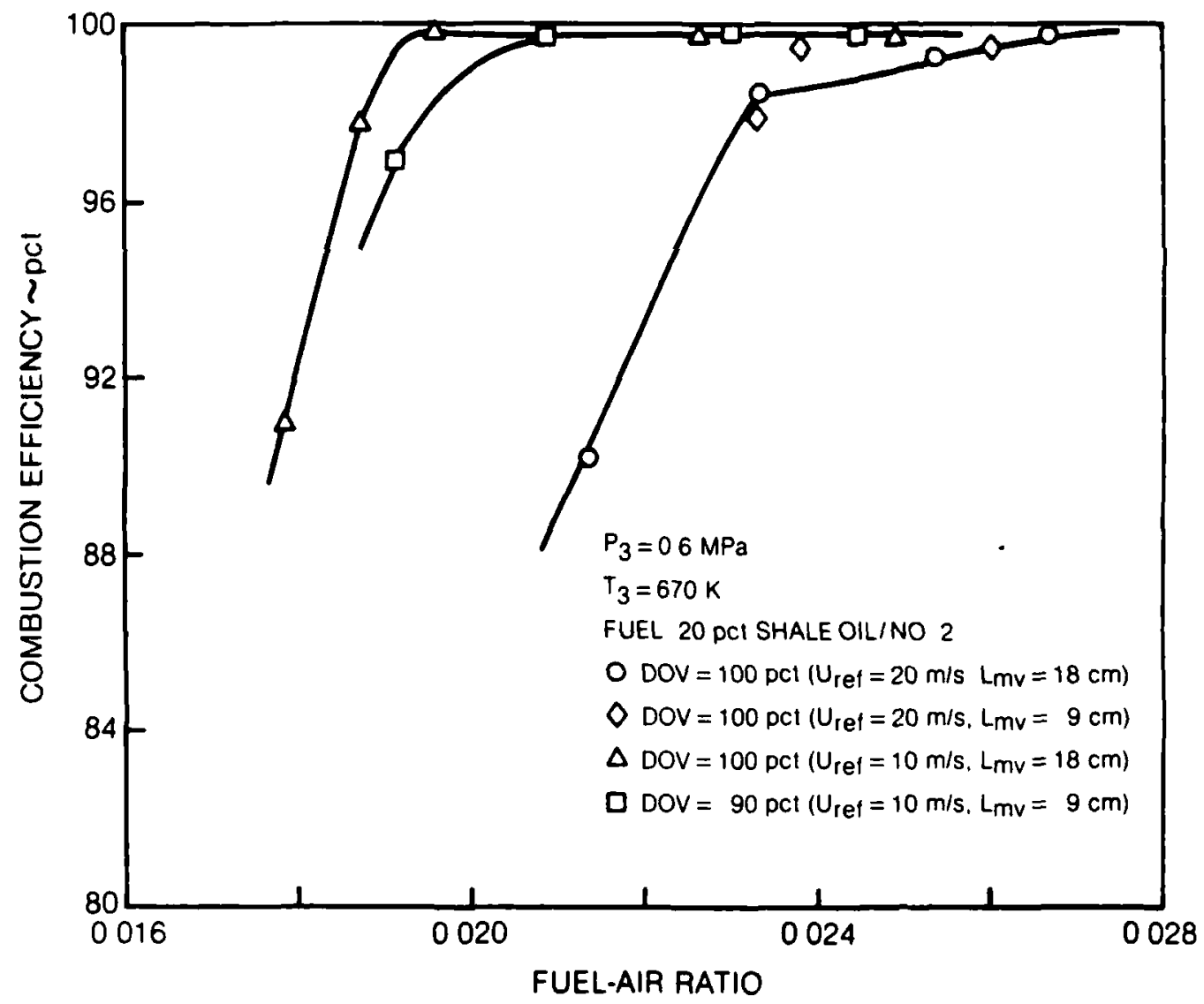

Figure 18 Influence of Degree of Vaporization on Reactor Performance Using Shale Oil Blend 


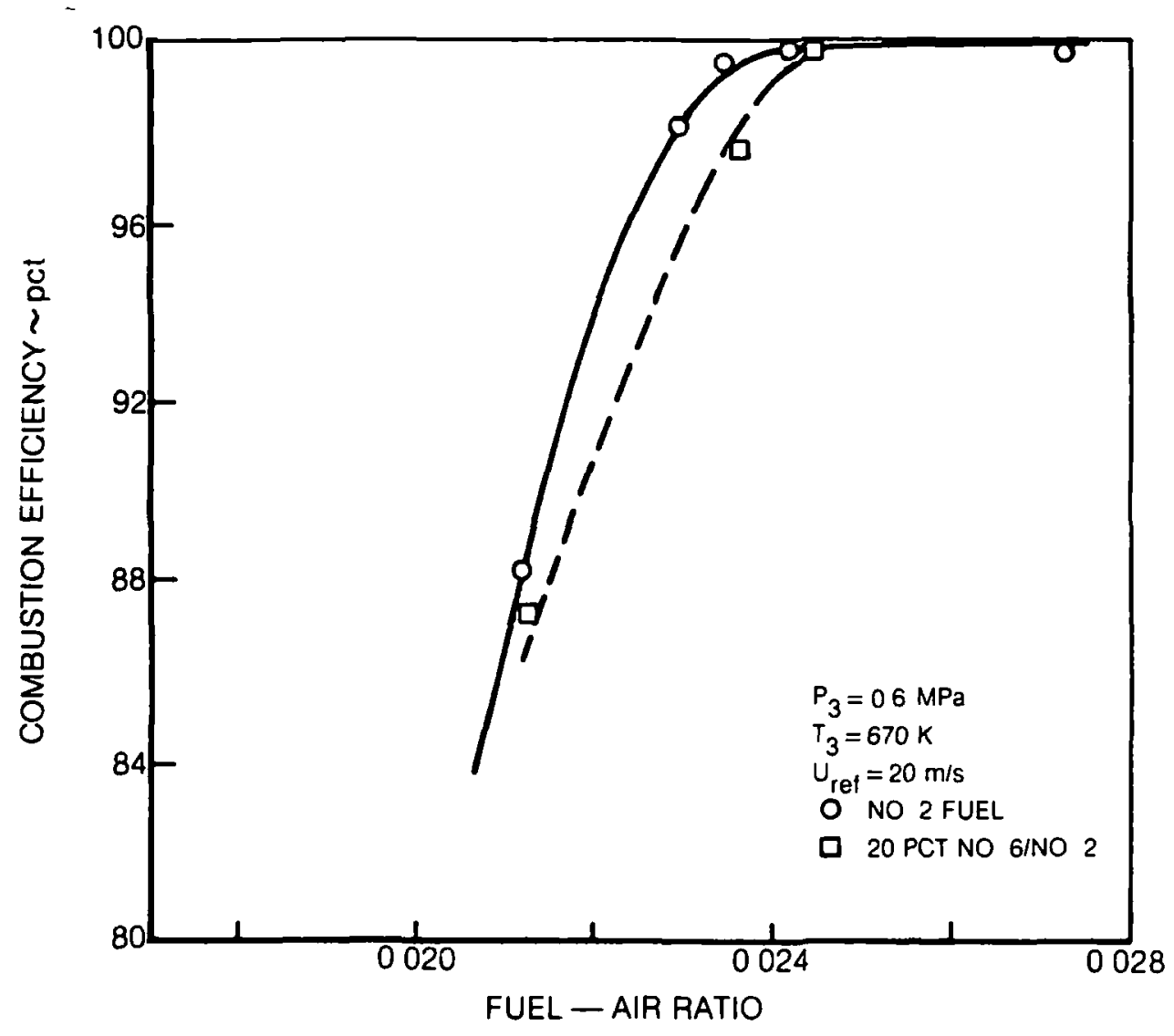

Figure 19 Performance with No. 2 Oil and 20-Percent No. 6 Blend 
R81-914724-18

\section{APPENDIX - DATA TABLES}




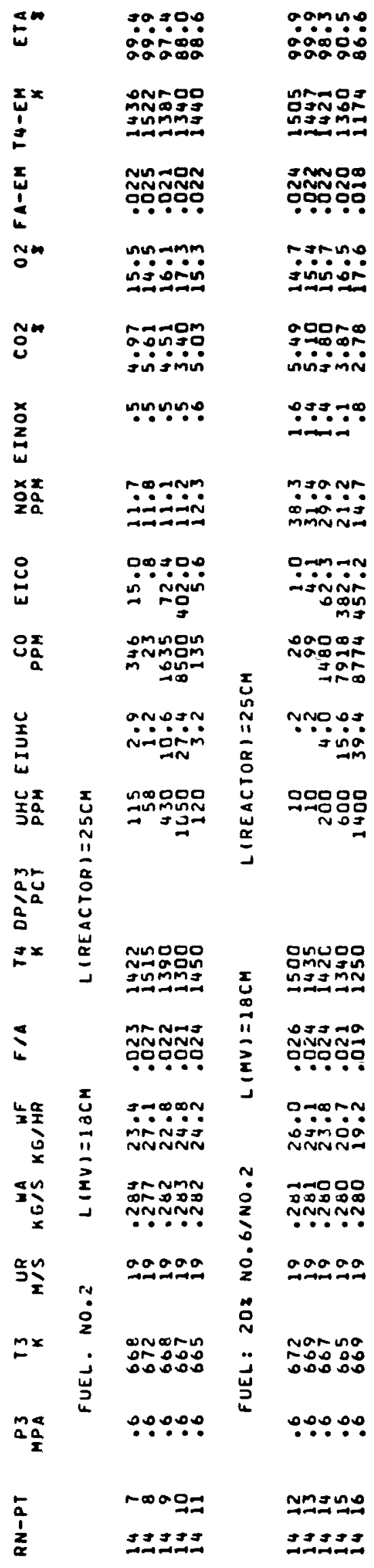




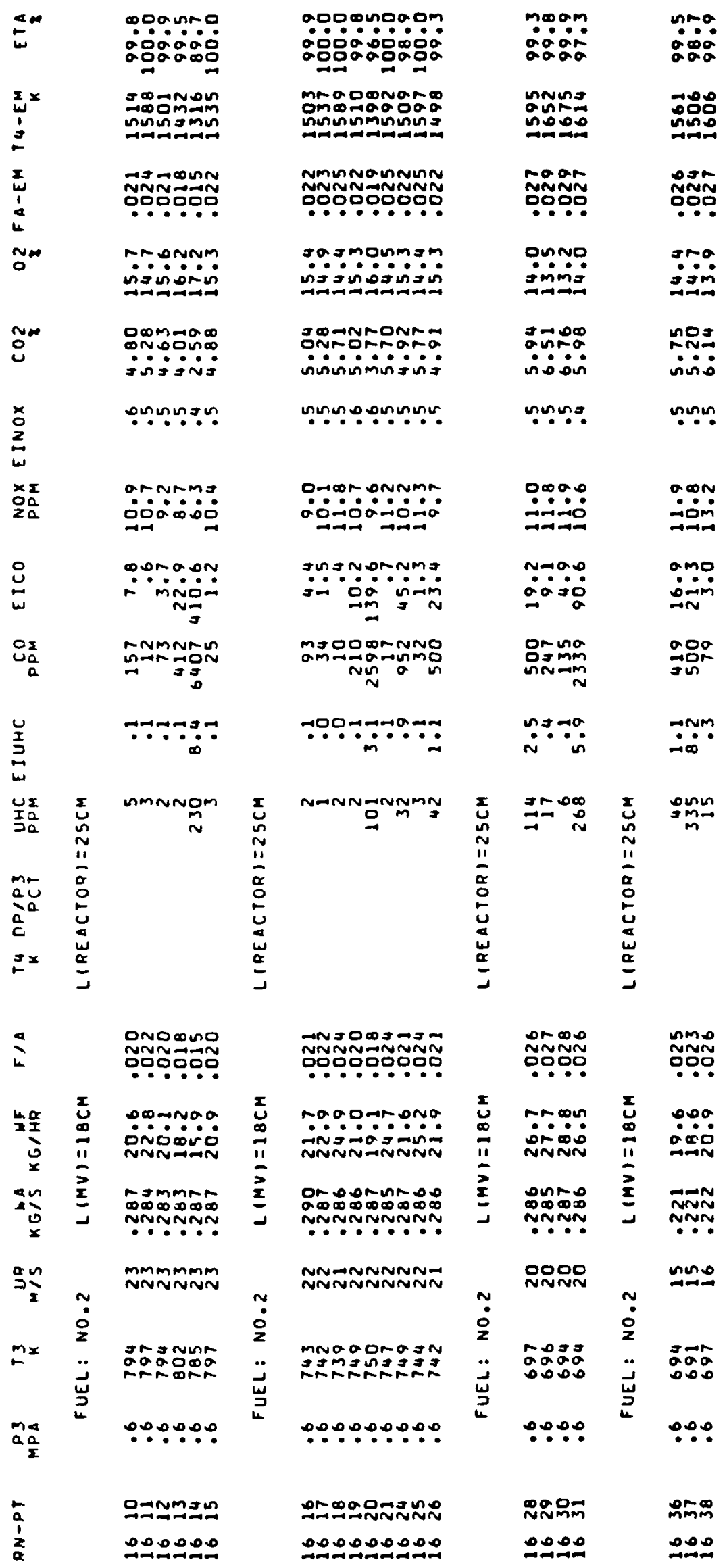




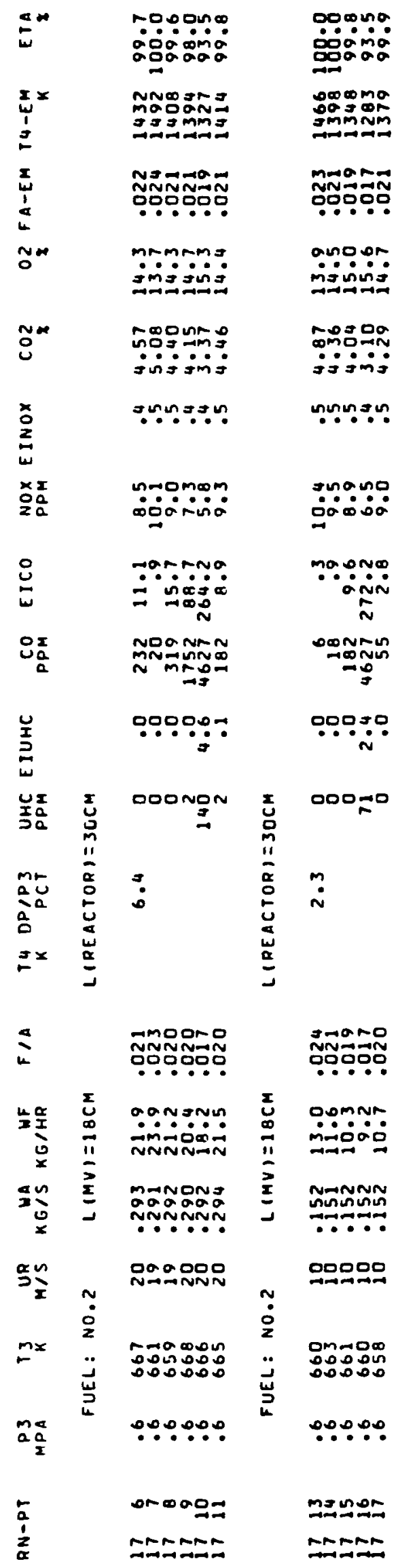




\begin{tabular}{|c|c|c|c|c|c|c|c|c|}
\hline$E$ & & 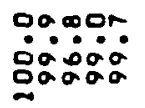 & & $\begin{array}{l}000000 \\
\because 00000 \\
000000\end{array}$ & & 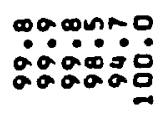 & & $\begin{array}{l}0 \infty 000 \\
0000 \\
0000\end{array}$ \\
\hline $\begin{array}{l}2 x \\
1 \\
1 \\
5\end{array}$ & & 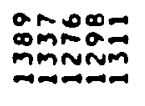 & & 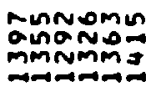 & & 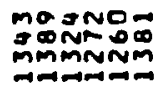 & & mpos \\
\hline $\begin{array}{l}x \\
w \\
1 \\
4\end{array}$ & & 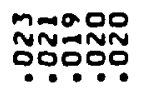 & & $\begin{array}{l}\text { MNOANNM } \\
\text { NNNANN } \\
\text { OOO.:. }\end{array}$ & & 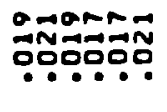 & & 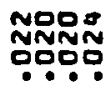 \\
\hline Now & & 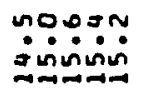 & & $\begin{array}{l}\text { SR:min } \\
\because \operatorname{Ming}:\end{array}$ & & iomo & & $\because \because$ \\
\hline 冓 & & 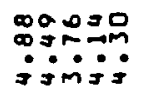 & & 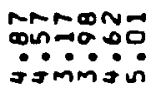 & & $\begin{array}{l}\text { ong } \\
\text { ing }\end{array}$ & & $\begin{array}{l}\because \infty \\
\because \because 1\end{array}$ \\
\hline 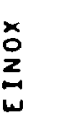 & & $\because \because \exists \mathrm{mm}$ & & จ.ำ: & & $\because \because$ & & $\because$ \\
\hline $\begin{array}{l}x=2 \\
x^{2} \\
00 \\
20\end{array}$ & & 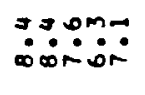 & & $\because \because \because 000$ & & 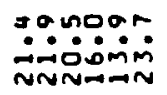 & & $\because \because \because$ \\
\hline 足 & & 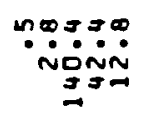 & & 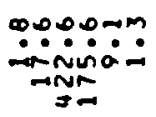 & & 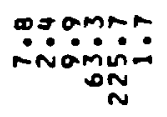 & & Mnar \\
\hline$\underbrace{O_{a}^{2}}_{0}$ & & 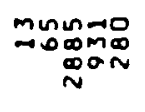 & & 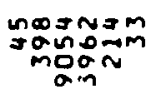 & u & 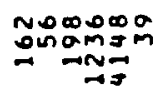 & & $\underset{\sim}{n \rightarrow n n m-1}$ \\
\hline w & & $\because \because \because \because$ & & $\because \because \because \div$ & $\begin{array}{c}0 \\
m \\
\frac{m}{\alpha}\end{array}$ & : & & 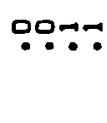 \\
\hline $\begin{array}{l}\text { ux } \\
\text { IIa } \\
J_{a}\end{array}$ & $\begin{array}{l}\mathbf{I} \\
u \\
⿱ 口 \\
\cdots \\
11\end{array}$ & Nmins $=$ & $\begin{array}{l}x \\
u \\
0 \\
m \\
11\end{array}$ & 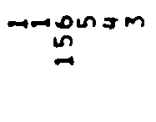 & 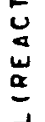 & ס000 & $\begin{array}{l}2 \\
y \\
0 \\
11 \\
1\end{array}$ & $\rightarrow$ NM \\
\hline $\begin{array}{l}m+ \\
a j \\
a \\
a\end{array}$ & $\begin{array}{l}\bar{\alpha} \\
\circ \\
\vdots \\
\alpha\end{array}$ & $\ddot{m}$ & $\begin{array}{l}a \\
0 \\
0 \\
\vdots \\
a\end{array}$ & $\because$ & \lrcorner & $\dddot{m}$ & $\begin{array}{l}0 \\
0 \\
0 \\
\vdots \\
0\end{array}$ & $\ddot{5}$ \\
\hline$\exists x$ & $\stackrel{w}{\alpha}$ & 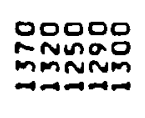 & $\underline{a}$ & $\begin{array}{l}\text { oogooo } \\
\text { ogiño요 } \\
\text { mminmmm }\end{array}$ & $\bigcup_{\infty}^{x}$ & 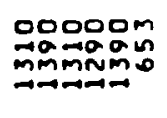 & $\underline{\mu}$ & 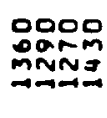 \\
\hline is & & 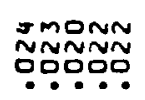 & & 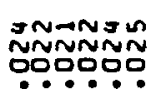 & $\frac{\overrightarrow{11}}{2}$ & 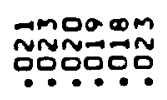 & & $\begin{array}{l}\text { NOON } \\
\text { NNNON } \\
\because \because: P O\end{array}$ \\
\hline$\sum_{\substack{x \\
x}}^{\frac{\alpha}{x}}$ & \begin{tabular}{l}
$x$ \\
$u$ \\
0 \\
\hdashline 11 \\
$y$
\end{tabular} & - :0man & $\begin{array}{l}x \\
u \\
\infty \\
\dddot{1} \\
\check{x}\end{array}$ & 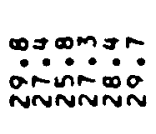 & $=$ & $\begin{array}{l}\rightarrow m m \infty n a \\
\text { Nmónom }\end{array}$ & $\begin{array}{l}z \\
0 \\
0 \\
0 \\
0\end{array}$ & $\operatorname{mas}_{\rightarrow \rightarrow \infty}^{m}$ \\
\hline an & $\underline{z}$ & $\begin{array}{l}\infty 0000 \\
000000 \\
00000 \\
\because \cdots \cdots\end{array}$ & $\vec{z}$ & 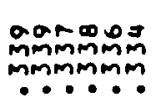 & $\begin{array}{l}n \\
\dot{0} \\
\dot{z}\end{array}$ & 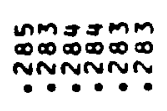 & $\underset{2}{2}$ & 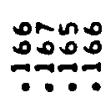 \\
\hline$\stackrel{\alpha}{\partial}=$ & $\stackrel{\sim}{\ddot{z}}$ & 00000 & $\because$ & ㅁNㅁNㅁN & $\begin{array}{l}\dot{0} \\
2 \\
\ddot{N}\end{array}$ & 000000 & $\begin{array}{l}\sim \\
\dot{0}\end{array}$ & 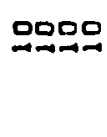 \\
\hline$m x$ & تّ & $\begin{array}{l}\text { Ommono } \\
\text { agagos } \\
\text { nnvivinus }\end{array}$ & $\ddot{\sim}$ & 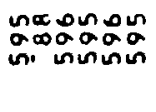 & تِّ & 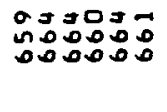 & $\ddot{\omega}$ & 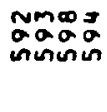 \\
\hline$m_{a} a$ & & $\because 0: 0 ?$ & & 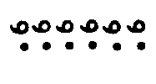 & & & & \\
\hline$\stackrel{\leftarrow}{a}$ & & $-\infty 00=$ & & uㅗㅍำ & & 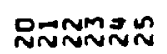 & & ponmog \\
\hline$z_{\alpha}$ & & $\stackrel{\infty}{\infty}$ & & $\stackrel{\infty}{\infty} \underbrace{\infty}_{-\infty} \infty \infty \infty$ & & 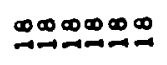 & & $\stackrel{\infty}{\infty}$ \\
\hline
\end{tabular}



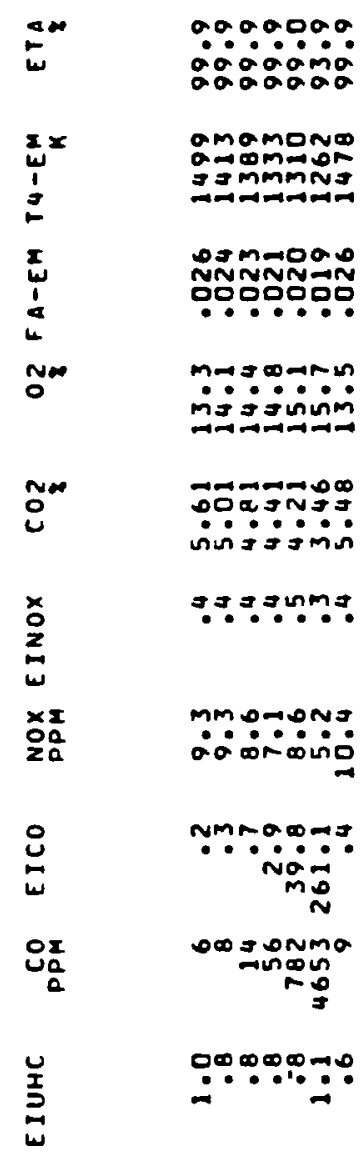

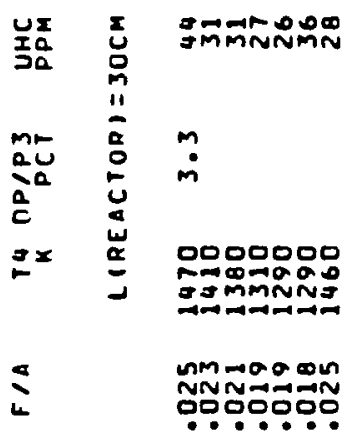

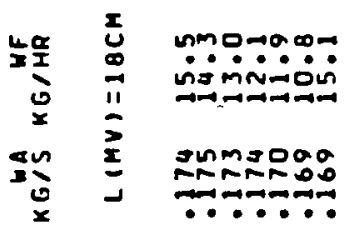

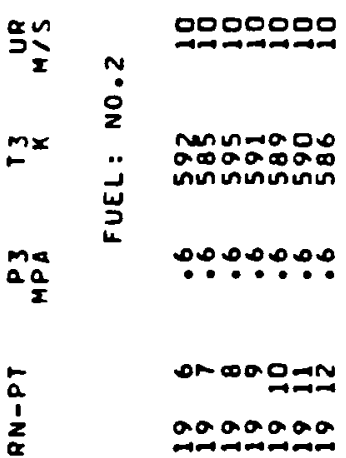




\begin{tabular}{|c|c|c|c|c|c|c|}
\hline$E^{\infty}$ & & 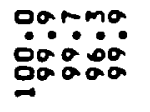 & & $\begin{array}{l}\text { Zno: } \\
\text { å00\% } \\
\text { åa }\end{array}$ & & 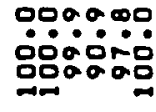 \\
\hline $\begin{array}{l}z x \\
w \\
\vdots \\
z\end{array}$ & & 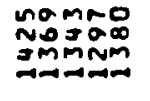 & & 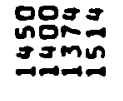 & & 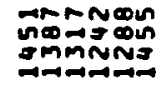 \\
\hline $\begin{array}{l}x \\
w \\
1 \\
a \\
k\end{array}$ & & 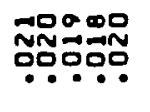 & & 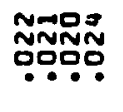 & & 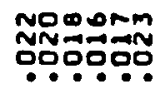 \\
\hline $\mathrm{N}^{\infty}$ & & 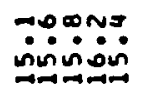 & & $\begin{array}{l}\rightarrow 0=0 \\
\text { ining: }\end{array}$ & & 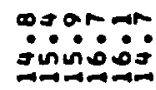 \\
\hline$\tilde{O}^{\infty}$ & & 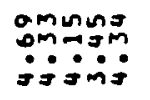 & & 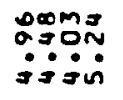 & & 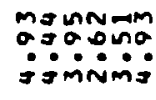 \\
\hline $\begin{array}{l}x \\
0 \\
z \\
w\end{array}$ & & $\because: \because: ㅁ$ & & : & & : \\
\hline 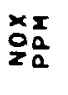 & & 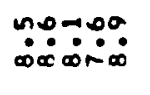 & & $\begin{array}{l}\because \sim \infty 0 \\
\because 000 \\
\text { miños }\end{array}$ & & 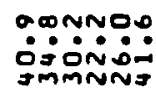 \\
\hline 怘 & & On: & & 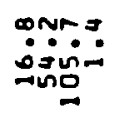 & & @innoun \\
\hline$u_{a}^{a x}$ & & $\operatorname{mmpos}_{n \rightarrow \infty}$ & İ & 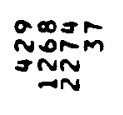 & z & " \\
\hline$\underset{n}{\underline{z}}$ & & $m m m g m$ & $\frac{11}{21}$ & 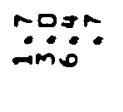 & $\begin{array}{l}m \\
\frac{m}{0} \\
0 \\
0\end{array}$ & $\because N M M N$ \\
\hline $\begin{array}{l}u_{x} \\
T_{2} \\
x_{0}\end{array}$ & $\begin{array}{l}\mathbf{2} \\
\text { O } \\
m \\
11\end{array}$ & $=0 \approx$ Nm & 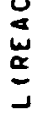 & $\underset{\sim N N}{\text { omam }}$ & 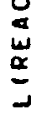 & $\alpha \infty \mathbb{N}^{\infty}$ \\
\hline $\begin{array}{l}m a \\
a v a \\
a \\
a\end{array}$ & $\begin{array}{l}a \\
0 \\
\vdots \\
0\end{array}$ & $\because$ & & $\because$ & & $\ddot{m}$ \\
\hline$\exists x$ & $\underset{\mu}{\alpha}$ & $\begin{array}{l}\text { nmooo } \\
\text { noñon } \\
\text { smiminm }\end{array}$ & $\underset{0}{\mathbf{0}}$ & 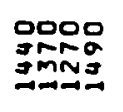 & $\underset{\infty}{\mathbf{D}}$ & 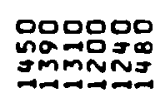 \\
\hline 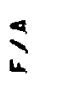 & & 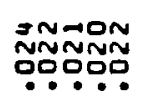 & $\ddot{z}$ & 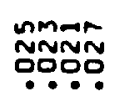 & $\frac{11}{2}$ & 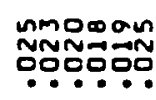 \\
\hline$\sum_{0}^{k}$ & $\begin{array}{l}\underbrace{2}_{0} \\
0 \\
11 \\
=\end{array}$ & 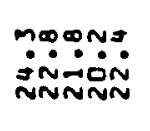 & $N$ & $\begin{array}{l}\text { ounmo } \\
\text { imin-in } \\
\text { NNNNN }\end{array}$ & $N$ & masuan \\
\hline$a_{0}^{4}$ & $\underline{\mathbf{z}}$ & 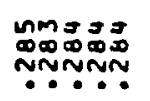 & $\sum_{\dot{2}}^{\dot{0}}$ & 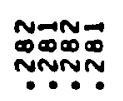 & 这 & 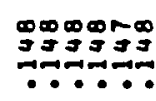 \\
\hline$\stackrel{2}{3} \simeq$ & & 00000. & 㞷 & 0000 & 㞷 & 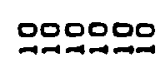 \\
\hline & $\ddot{0}$ & & $\stackrel{0}{\sim}$ & & 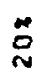 & \\
\hline$m x$ & $\ddot{\vec{u}}$ & 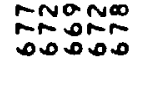 & $\ddot{~}$ & $\begin{array}{l}-1 N N O \\
-N \sim \infty \\
0000\end{array}$ & $\ddot{~}$ & 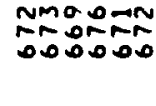 \\
\hline $\mathrm{ma}_{\frac{2}{2}}$ & & $\because 0$ & & $\because \because$ & & 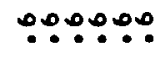 \\
\hline$a$ & & ondog & & 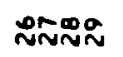 & & 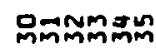 \\
\hline 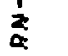 & & DOOOOO & & OOOOO & & $\begin{array}{l}\text { OOOOOODO } \\
\text { NNNNNN }\end{array}$ \\
\hline
\end{tabular}




\begin{tabular}{|c|c|c|c|c|c|c|c|c|c|c|c|c|}
\hline$E$ & & 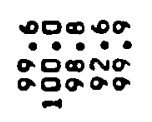 & & 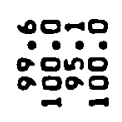 & & 范 & & 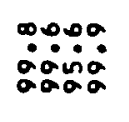 & & 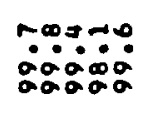 & & $\begin{array}{l}\therefore: \\
\therefore \circ\end{array}$ \\
\hline $\begin{array}{l}x x \\
\vdots \\
\vdots \\
\vdots\end{array}$ & & 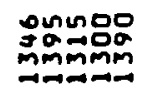 & & $\begin{array}{l}\text { aring } \\
\text { mpinmm } \\
\text { mimnm }\end{array}$ & & 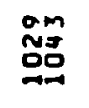 & & 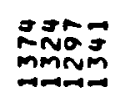 & & 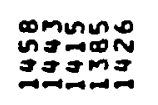 & & so \\
\hline 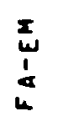 & & 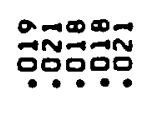 & & 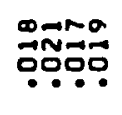 & & $\underset{0}{M}$ & & 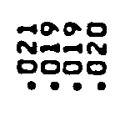 & & 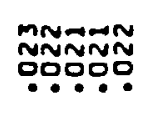 & & $\ddot{0}$ \\
\hline ח & & 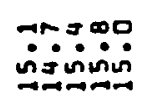 & & na: & & $\stackrel{\infty}{\ddot{y}}$ & & $\begin{array}{l}\text { oxpm } \\
\text { ñining }\end{array}$ & & 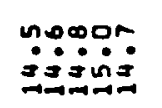 & & 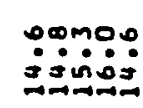 \\
\hline$\stackrel{\sim \infty}{0}$ & & 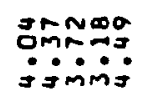 & & 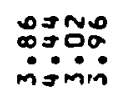 & & 戒品 & & 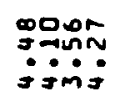 & & 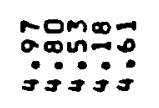 & & 명ㅇ \\
\hline $\begin{array}{l}\text { x } \\
0 \\
2 \\
w\end{array}$ & & 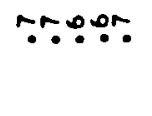 & & $\because \because \because \because$ & & $m$ & & •: & & :ヘnmñ & & \\
\hline $\begin{array}{l}x=1 \\
\text { oa } \\
\text { 2a }\end{array}$ & & $\underset{m \rightarrow=0}{\operatorname{minn}}$ & & mivo: & & $\ddot{0}$ & & 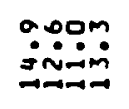 & & 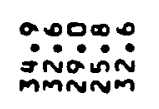 & & \\
\hline س & & 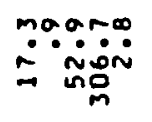 & & 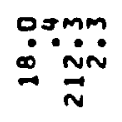 & & 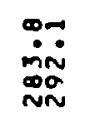 & & $\underset{\sim \infty}{0 \infty n}$ & & n口:o:日 & & 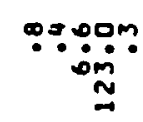 \\
\hline$U_{\frac{a}{a}}^{O_{0}}$ & & 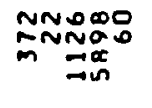 & & 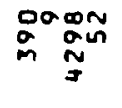 & & $\mathfrak{n}_{0.0}^{n_{0}}$ & & $\underset{\text { Non }}{\text { Non }}$ & $\mathbf{x}$ & 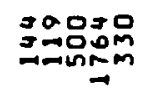 & $\underline{\mathbf{I}}$ & $\underset{\sim}{n \rightarrow a g a r}$ \\
\hline 堊 & & $\because 00$ יח & & ORno & & $\begin{array}{l}0: 0 \\
\ddot{0} 00 \\
00\end{array}$ & & ت̊: & 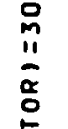 & 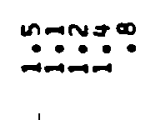 & $\begin{array}{l}0 \\
i 1 \\
\frac{p}{\alpha} \\
0 \\
0\end{array}$ & ? \\
\hline $\begin{array}{l}\text { Ux } \\
\text { İa } \\
\text { Sa }\end{array}$ & $\stackrel{I}{\breve{g}}$ & 00- & 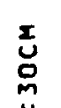 & oono & 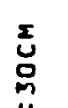 & $\begin{array}{l}\text { on } \\
\text { 范 } \\
\text { o. }\end{array}$ & $\underset{⿱ 丷}{\mathbf{I}}$ & 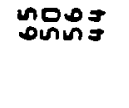 & $\begin{array}{l}u \\
\underline{u} \\
\underline{\alpha}\end{array}$ & 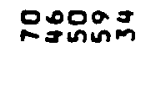 & 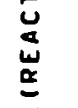 & ENN. \\
\hline 垈 & 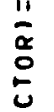 & $\dot{0}$ & $\begin{array}{l}\frac{1}{\alpha} \\
\vdots \\
0\end{array}$ & $\dot{m}$ & $\begin{array}{l}\frac{11}{\alpha} \\
\stackrel{0}{2}\end{array}$ & & $\begin{array}{l}\frac{11}{\alpha} \\
0 \\
0\end{array}$ & $\ddot{m}$ & 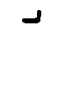 & $\dot{0}$ & ـ & $\ddot{m}$ \\
\hline$E^{x}$ & $\stackrel{\stackrel{a}{\alpha}}{a}$ & 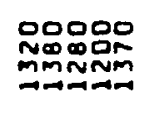 & J & $\begin{array}{l}\text { oogon } \\
\text { manimp } \\
\text { mann }\end{array}$ & $\underset{\omega}{\tilde{\alpha}}$ & & $\begin{array}{l}\underline{a} \\
\underline{\alpha} \\
\underline{\alpha}\end{array}$ & 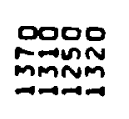 & $u_{0}^{x}$ & 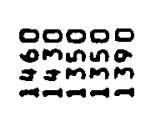 & $u_{0}^{2}$ & 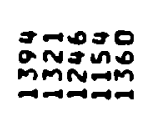 \\
\hline$=$ & & 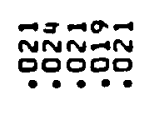 & & 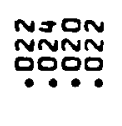 & & $\begin{array}{l}N \text { N } \\
\mathbb{N} \\
\because\end{array}$ & & 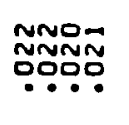 & $\frac{\pi}{3}$ & 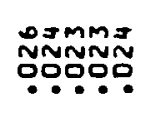 & $\frac{\pi}{2}$ & 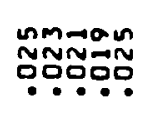 \\
\hline 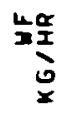 & $\begin{array}{l}x \\
u \\
0 \\
11 \\
z\end{array}$ & 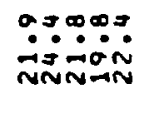 & $\begin{array}{l}\mathbf{I} \\
0 \\
0 \\
11 \\
z\end{array}$ & 足 & $\begin{array}{l}x \\
\vdots \\
0 \\
11\end{array}$ & $\underset{m i m}{\operatorname{mim}}$ & $\begin{array}{l}\mathbf{x} \\
0 \\
0 \\
11\end{array}$ & 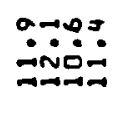 & $\simeq$ & 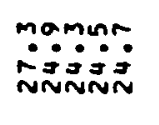 & N & umnNm \\
\hline 無 & $\stackrel{\Sigma}{J}$ & 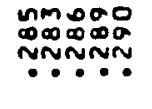 & $\underline{x}$ & 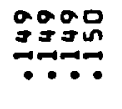 & $\underline{\Sigma}$ & $\begin{array}{l}00 \\
00 \\
\because 0\end{array}$ & $\underline{\mathbf{x}}$ & 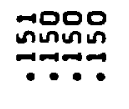 & 莫 & 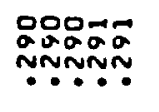 & $\sum_{\substack{0 \\
z}}^{\dot{z}}$ & 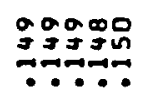 \\
\hline$\stackrel{\alpha u}{s}$ & $\dddot{0}$ & 00000 & $\dddot{0}$ & 9000 & $\dddot{\vdots}$ & $\therefore$ & $\stackrel{n}{\dot{0}}$ & 0000 & 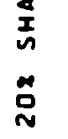 & aㅁNㅁㅁㅁ & 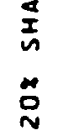 & ספר \\
\hline$a_{a 2}^{m a}$ & $\ddot{~}$ & 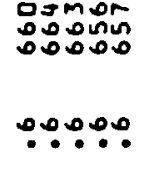 & $\ddot{\vec{\omega}}$ & 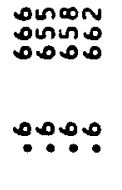 & تّ & $\begin{array}{l}\text { Non } \\
\text { inin } \\
\because \therefore\end{array}$ & تّ̈ & $\begin{array}{l}\underset{\text { mimmin }}{\text { mome }} \\
\because \therefore 0:\end{array}$ & $\underset{u}{\ddot{u}}$ & 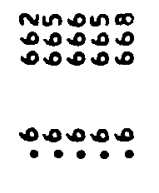 & $\underset{\vec{u}}{\vec{J}}$ & 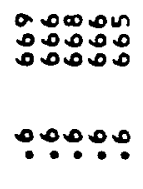 \\
\hline a & & orag & & znen & & 9 & & 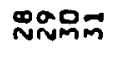 & & mñming & & 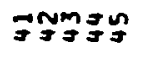 \\
\hline 2 & & กีNतีNतี & & 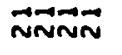 & & $\overrightarrow{n N}$ & & $\vec{N} \tilde{N} \tilde{N}$ & & जีNÄNÃ & & $\vec{N} \vec{N} \tilde{N} \tilde{N} \vec{N}$ \\
\hline
\end{tabular}




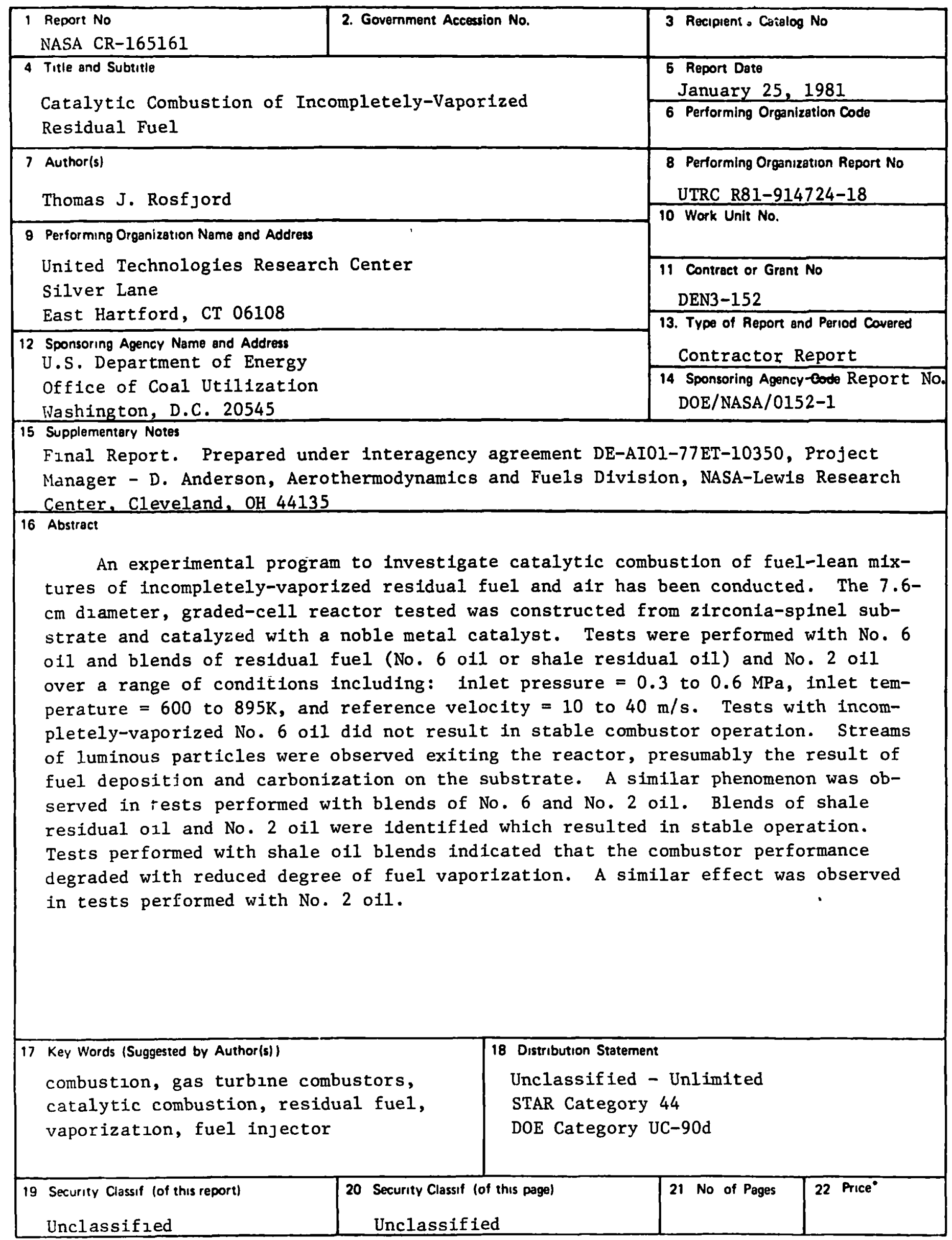

* For sale by the National Technical Information Service, Springfield, Virginia 22151 